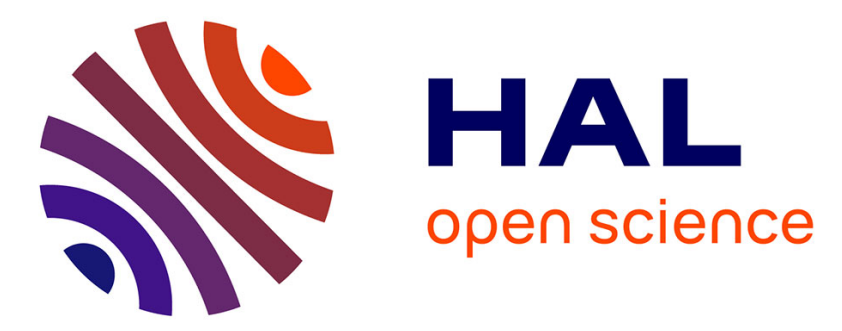

\title{
High-quality lowest-frequency normal mode strain observations at the Black Forest Observatory (SW-Germany) and comparison with horizontal broad-band seismometer data and synthetics
}

K Zürn, E M G Ferreira, K Widmer-Schnidrig, L Lentas, L Rivera, E Clévédé

\section{To cite this version:}

K Zürn, E M G Ferreira, K Widmer-Schnidrig, L Lentas, L Rivera, et al.. High-quality lowestfrequency normal mode strain observations at the Black Forest Observatory (SW-Germany) and comparison with horizontal broad-band seismometer data and synthetics. Geophysical Journal International, 2015, 203 (3), pp.1787-1803. 10.1093/gji/ggv381 . insu-01390070

\section{HAL Id: insu-01390070 \\ https://hal-insu.archives-ouvertes.fr/insu-01390070}

Submitted on 31 Oct 2016

HAL is a multi-disciplinary open access archive for the deposit and dissemination of scientific research documents, whether they are published or not. The documents may come from teaching and research institutions in France or abroad, or from public or private research centers.
L'archive ouverte pluridisciplinaire HAL, est destinée au dépôt et à la diffusion de documents scientifiques de niveau recherche, publiés ou non, émanant des établissements d'enseignement et de recherche français ou étrangers, des laboratoires publics ou privés. 


\title{
High-quality lowest-frequency normal mode strain observations at the Black Forest Observatory (SW-Germany) and comparison with horizontal broad-band seismometer data and synthetics
}

\author{
W. Zürn, ${ }^{1}$ A.M.G. Ferreira, ${ }^{2,3}$ R. Widmer-Schnidrig, ${ }^{1}$ K. Lentas, ${ }^{4}$ L. Rivera ${ }^{5}$ \\ and E. Clévédé ${ }^{6}$ \\ ${ }^{1}$ Black Forest Observatory (Schiltach), Karlsruhe Institute of Technology and Stuttgart University, Heubach 206, \\ D-77709 Wolfach, Germany.E-mail: walter.zuern@partner.kit.edu \\ ${ }^{2}$ Department of Earth Sciences, University College London, London, United Kingdom \\ ${ }^{3}$ CEris, ICIST, Instituto Superior Técnico, Universidade de Lisboa, Lisbon, Portugal \\ ${ }^{4}$ International Seismological Centre, Pipers Lane, Thatcham, Berkshire, United Kingdom \\ ${ }^{5}$ Institut de Physique du Globe de Strasbourg, CNRS/University of Strasbourg, UMR 7516, Strasbourg, France \\ ${ }^{6}$ Institut de Physique du Globe de Paris, UMR 7154, Paris, France
}

Accepted 2015 September 9. Received 2015 September 8; in original form 2015 February 20

\begin{abstract}
SUMMAR Y
We present spectra concentrating on the lowest-frequency normal modes of the Earth obtained from records of the invar-wire strainmeters and STS-1 broad-band seismometers located in the Black Forest Observatory, Germany after the disastrous earthquakes off the NW coast of Sumatra in 2004 and off the coast near Tohoku, Japan in 2011. We compare the spectra to ones obtained from synthetic seismograms computed using a mode summation technique for an anelastic, elliptical, rotating, spherically symmetric Earth model. The synthetics include strainstrain-coupling effects by using coupling coefficients obtained from comparisons between Earth tide signals recorded by the strainmeters and synthetic tidal records. We show that for the low-frequency toroidal and spheroidal modes up to $1 \mathrm{mHz}$, the strainmeters produce better signal-to-noise ratios than the broad-band horizontal seismometers. Overall, the comparison with the synthetics is satisfactory but not as good as for vertical accelerations. In particular, we demonstrate the high quality of the strainmeter data by showing the Coriolis splitting of toroidal modes for the first time in individual records, the first clear observation of the singlet ${ }_{2} S_{1}^{0}$ and the detection of the fundamental radial mode ${ }_{0} S_{0}$ with good signal-to-noise ratio and with a strain amplitude of $10^{-11}$. We also identify the latter mode in a record of the Isabella strainmeter after the great Chilean quake in 1960, the detection of which was missed by the original studies.
\end{abstract}

Key words: Transient deformation; Broad-band seismometers; Surface waves and free oscillations.

\section{INTRODUCTION}

Models of 1-D and 3-D Earth structure have greatly benefited from observations of the free oscillations of the Earth since 1960. For example, the Preliminary Reference Earth Model (PREM) by Dziewonski \& Anderson (1981) is based on information from normal modes as well as on traveltimes of body waves and surface wave phase velocities. The very first global 3-D model of the Earth's mantle was derived from the peak shifts of free oscillation multiplets by Masters et al. (1982). After these early applications, numerous studies exploiting free oscillation observations were performed based on a dramatic increase of relevant observation stations all over the globe (e.g. Widmer-Schnidrig \& Laske 2007). Ritzwoller \& Lavely (1995), Widmer-Schnidrig (2003) and Häfner \& Widmer-
Schnidrig (2013) pointed out that only very low frequency normal modes can provide information on the density structure of the Earth independent of seismic velocity structure. In addition, for studies of the source parameters of the greatest earthquakes information from normal mode seismology is of vital importance (e.g. Gilbert \& Dziewonski 1975; Stein \& Okal 2005; Lentas et al. 2014). However, in both types of studies normal modes observed with vertical component accelerometers outnumber the ones observed with horizontal components. For example, splitting functions and/or coefficients are virtually non-existent for toroidal modes to the best of our knowledge.

When after the great 1960 Chilean earthquake $\left(M_{\mathrm{w}} 9.5\right)$ the Earth's free oscillations were for the first time clearly identified in the spectra of seismic records from a small number of 


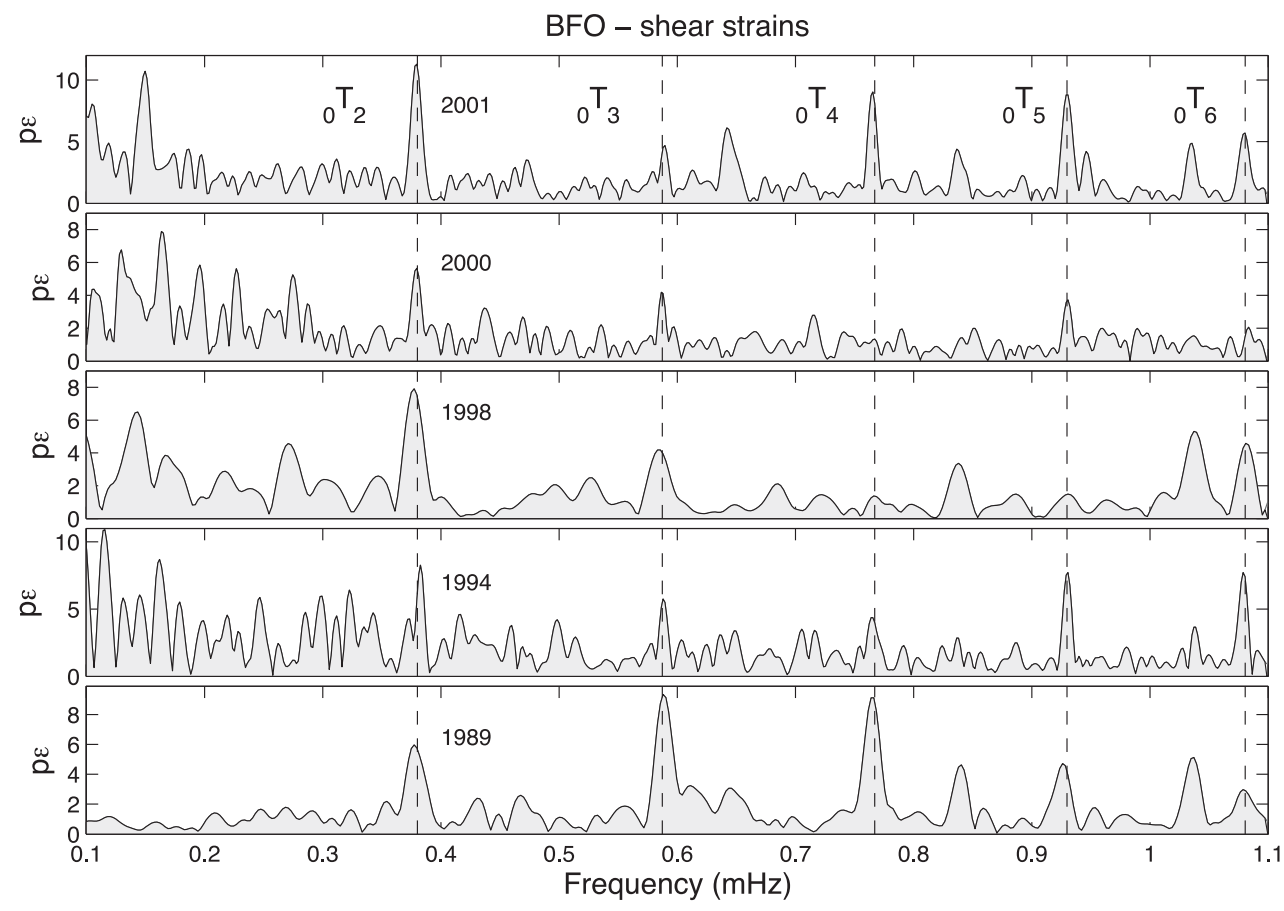

Figure 1. Identification of ${ }_{0} T_{2}$ in the spectra of strain records from BFO after several very large quakes. For every event, the data from the three linear strainmeters were linearly combined to represent shear strain in a coordinate system rotated with respect to the local geographical system to obtain maximum SNR for ${ }_{0} T_{2}$. Time-series were multiplied by a Hann taper and padded with zeros before FFTs were computed. The presence of peaks at the well-known frequency of ${ }_{0} T_{2}(0.38 \mathrm{mHz})$ was in each case corroborated by the absence of a peak in the linear combination representing areal strain (not shown). For each quake, the length of the Hann window and the counterclockwise $(\mathrm{ccw})$ rotation of the local coordinate system are given in parentheses below. The pressure admittances to linear strains are given in Table 1 for the four later quakes. No pressure correction was applied to the records from the Macquarie event. Note that the efficiency of the pressure correction for shear strain is much lower than the one for areal strain (see Fig. 2). From bottom to top: 1989 Macquarie Ridge $\left(36 \mathrm{hr}, 85^{\circ}\right.$, no pressure corrections applied), 1994 Shikotan $\left(64 \mathrm{hr}, 112^{\circ}\right), 1998$ Balleny Islands $\left(30 \mathrm{hr}, 35^{\circ}\right), 2000 \mathrm{Wharton}$ Basin $\left(60 \mathrm{hr}, 22.5^{\circ}\right)$ and 2001 Peru $\left(60 \mathrm{hr}, 120^{\circ}\right)$.

long-period instruments, the $24 \mathrm{~m}$ quartz-tube strainmeters at Isabella, California (Azimuth N32 ${ }^{\circ} \mathrm{W}$ ) and Naña, Peru (Benioff 1959; Benioff et al. 1961) were among them. The spectrum from the best record (Isabella) shows all the low-degree fundamental spheroidal and toroidal modes (with the exception specified below) above the noise, with clear splitting of ${ }_{0} S_{2}$ and ${ }_{0} S_{3}$. The strainmeters at Isabella also recorded the 1964 Alaskan earthquake (Smith 1966) with good quality. In that paper, the author makes the statement: 'The largest gap in data on free oscillations of the Earth remains the period of the fundamental toroidal mode of order 2 . It is not clear that this mode has ever been observed and adequately measured'. In contrast, Derr (1969) in his summary calls the Isabella strainmeter record the best evidence for ${ }_{0} T_{2}$. However, the statement by Smith was repeated by Gilbert (personal communication, 1981) long after the records from the 1977 Sumbawa quake had been exploited. Widmer et al. (1992) reanalysed a digitized version of the Isabella record from the Chilean quake and verified that ${ }_{0} T_{2}$ cannot really be identified in that record. In Section 7 of this study, we revisit these observations comparing the Isabella strain data from 1960 with the strain data from the Black Forest Observatory (BFO) in SW-Germany $\left(48.33^{\circ} \mathrm{N}, 8.33^{\circ} \mathrm{E}, 589 \mathrm{~m}\right.$ amsl) recorded after the disastrous N-Sumatra-Andaman Islands quake (hereafter referred to as Aceh quake) on 2004 December 26.

Using data from the strainmeter array at BFO, Widmer et al. (1992) were able to unambiguously (Dahlen \& Tromp 1998, p. 287) identify ${ }_{0} T_{2}$ after the 1989 Macquarie Islands (May 23, $M_{\mathrm{w}} 8.0$ ) event. They were also able to repeat this identification in the strain records from the following strong earthquakes (Zürn \& Widmer-
Schnidrig 2002): 1994 Shikotan (October 4, $M_{\mathrm{w}} 8.3$ ), 1998 Balleny Islands (March 25, $M_{\mathrm{w}} 8.1$ ), 2000 Wharton Basin (June 18, $M_{\mathrm{w}} 7.9$ ) and 2001 Peru (June 23, $M_{\mathrm{w}} 8.4$ ). The Balleny Islands result is also reported by Zürn et al. (2000; Fig. 1).

The strainmeter array at BFO consists of three $10 \mathrm{~m}$ long invarwire extensometers with azimuths $\mathrm{N} 2{ }^{\circ} \mathrm{E}, \mathrm{N} 60^{\circ} \mathrm{E}$ and $\mathrm{N} 300^{\circ} \mathrm{E}$. These are improved versions of the instruments described by King \& Bilham (1976; see also Agnew 1986). The improvements consist of better displacement transducers (TESA-Group, Switzerland) with much less self-noise, the addition of in situ calibration devices at the opposite end from the transducers (crapaudines, e.g. Agnew 1986) and more extensive shielding against ambient temperature variations. They are located $170 \mathrm{~m}$ below the surface in tunnels cut into granite and are additionally shielded by an efficient air-lock which strongly attenuates ambient pressure variations at mode frequencies. Actually a second air-lock was installed in 2009 (between the two megaquakes). Forbriger (2007) has found that despite the ferromagnetism of invar the strainmeters at BFO do not respond visibly to geomagnetic storms. Descriptions of the observatory and the strainmeter array can be found in Richter et al. (1995) and Widmer et al. (1992).

Fig. 1 summarizes observations of mode ${ }_{0} T_{2}$ at BFO's strainmeters after several large earthquakes. For each spectrum, the three strainmeter records were linearly combined to yield the shear strains with the local coordinate system selected by rotation (with respect to the local geographical system) to give optimal signal-to-noise ratio (SNR) for ${ }_{0} T_{2}$. The strain records were calibrated, detided, and using an optimal real air pressure admittance to strain the noise 
was reduced with the help of the locally recorded atmospheric pressure (see Section 3.2 below). The identification of the peak at the predicted frequency of $T_{2}$ in the spectra of the shear strains is in all five cases corroborated by its absence in the corresponding spectra of areal strain (Widmer et al. 1992).

In this paper, we present new spectra of strain-seismograms from the three strainmeters at BFO and compare them with spectra of seismograms from the horizontal broad-band STS-1 seismometers at the same station recorded after two megaquakes. In the next section, these quakes are briefly identified and previous free oscillation work from corresponding records is referenced. The processing of the data from BFO is described in Section 3, with two subsections concentrating on the effects atmospheric pressure noise has on the seismograms and on the improvements which can be obtained by simple linear regressions with locally recorded barometric pressure. Our computations of corresponding synthetic strain and acceleration seismograms are described in Section 4. In Section 5, we compare and discuss the observed linear, areal and shear strain spectra with horizontal acceleration spectra and the corresponding synthetic spectra. We find that for the lowest frequency modes the SNR is better for the strain records than for the horizontal accelerograms. Section 6 deals with the rare observation of the fundamental radial mode ${ }_{0} S_{0}$ in strain and with an internal consistency check between strain and vertical acceleration observations. In Section 7, we compare different spectra from our best strainmeter with similar ones from the Isabella strainmeter obtained after the great Chilean earthquake in 1960 and show that the mode ${ }_{0} S_{0}$ can be identified in that famous record. Section 8 summarizes our conclusions. In Appendix A, we compare vertical accelerogram spectra from BFO from the two quakes with the corresponding synthetics and in Appendix B we demonstrate that normal mode spectral shapes differ locally for different horizontal accelerometers.

Our amplitude spectra (Fast Fourier transforms, FFT below) of the time-series multiplied by Hann tapers are normalized such that a harmonic oscillation with constant amplitude $A$ would have the value $A$ in the amplitude spectra.

We use the abbreviations $\mathrm{n} \epsilon$ and $\mathrm{p} \epsilon$ for $10^{-9}$ and $10^{-12}$, respectively for strain (or relative displacement) throughout the paper.

\section{MEGAQUAKES}

The Aceh quake on 2004 December $26\left(M_{\mathrm{w}}=9.1-9.3\right)$ was the strongest event since 1964 and, of course, excited the free vibrations of the Earth to large initial amplitudes. The global seismic network (GSN) with its broad-band seismographs provided an unprecedented large data set for free oscillation studies (e.g. Butler et al. 2004; Davis et al. 2005; Park et al. 2005). Moreover, the Global Geodynamics network (GGP) of superconducting gravimeters provided high-quality vertical acceleration records especially for studies of the low-degree spheroidal modes (e.g. Rosat et al. 2005, 2007; Lambotte et al. 2006a; Roult et al. 2006; Häfner \& WidmerSchnidrig 2013). Lambotte et al. (2006a) first demonstrated that it is possible to use the phases of normal modes to constrain source finiteness.

In addition, fine free oscillation spectra were also obtained from a few more exotic instruments: long baseline fluid tiltmeters in Luxembourg and at BFO (Ferreira et al. 2006), the giant horizontal pendulums in the Grotta Gigante near Trieste (Braitenberg \& Zadro 2007), the laser strainmeters in the Gran Sasso observatory (Park et al. 2008) and a stack from a small-aperture array of five Askania borehole tiltmeters installed around the site of the $9 \mathrm{~km}$ deep Continental Deep Drillhole $\left(\mathrm{K}_{T} \mathrm{~B}\right)$ in southeastern Germany
(Jentzsch et al. 2005). Takemoto et al. (2004) describe $100 \mathrm{~m}$ long laser strainmeters in the $1000 \mathrm{~m}$ deep Kamioka mine in Japan. Araya et al. (2010) claim that these are the most accurate strainmeters in the world, however, unfortunately to our best knowledge they have not published free oscillation spectra from these devices.

On 2011 March 11, the Tohoku quake with a moment magnitude $M_{\mathrm{w}}=9.1$ struck and provided excellent normal mode spectra again (Okal 2012; Tanimoto et al. 2012; Bogiatzis \& Ishii 2014; Lentas et al. 2014). For example, Lentas et al. (2014) succeeded in constraining not only the moment tensor of this event, but also its source duration and fault length (giving average rupture speed) in good agreement with totally different types of data. Tanimoto et al. (2012) found that a slow slip component was not identifiable for this event, while for the Aceh event this was an important feature to explain the low-frequency data.

We concentrate in this paper on these two largest quakes of the last half century: Aceh 2004 and Tohoku 2011.

\section{DATA PROCESSING}

\subsection{General}

In the following, we show spectra from strainmeter data and broadband seismograms with a length of $220 \mathrm{hr}$. This length was chosen because all five singlets of the 'football' mode ${ }_{0} S_{2}$ are resolved when a Hann window is multiplied onto these time-series to reduce spectral leakage. Mean values and tides are removed from all the series first, the latter by least squares fitting sinusoids and cosinusoids with the frequencies of the tides $M_{2}, K_{1}, S_{2}, O_{1}, N_{2}, K_{2}, P_{1}, Q_{1}$, $M_{3}$ and $M_{4}$. The transfer function of the strainmeters is frequency independent and their output is proportional to the relative change in length from $0.04 \mathrm{~Hz}$ down to zero frequency. However, the instrumental drift of the wire strainmeters due to creep is rather large and limits their usefulness for signals with periods longer than a few days. These data are converted to units of $p \epsilon$. For the seismograms from the STS-1 horizontal seismometers, the instrument response is removed in the frequency domain and the data converted to ground accelerations in units of $\mathrm{pm} \mathrm{s}^{-2}$. While these steps are not necessary to compute spectra and compare SNRs, they are needed for reducing the noise caused by barometric pressure fluctuations in both types of data (e.g. Zürn et al. 2007) and for computing areal and shear strains. These pressure corrections are described in Section 3.2. After the pressure corrections have been applied the data are multiplied by a Hann window and then Fourier transformed.

\subsubsection{Gain loss of the $N 60^{\circ}$ E-strainmeter during the Tohoku event}

Unfortunately the $N 60^{\circ} \mathrm{E}$-strainmeter suffered a loss of gain around the time of the Tohoku quake in 2011. In situ calibrations were performed on 2011 January 26 and April 11 using the crapaudines (e.g. Agnew 1986). On the first date the gain was found nominal, on the second date it was reduced to 0.26 per cent of nominal (i.e. by a factor of 400). The second calibration was carried out because a strong suspicion had arisen that something was amiss and subsequently a corroded cable between the displacement transducer and its electronics was detected as the culprit. The comparison of the uncorrected $220 \mathrm{hr}$ Tohoku record from this instrument with the synthetics indicated that during this time the problem already existed. However, we are unable to explain physically why this damage started to appear at the time of the Tohoku quake. In the Supporting Information to this paper, we demonstrate in Fig. S1 that 
after the event the recorded amplitudes of the Earth tide decreased conspicuously.

Since the tidal signal is much larger than the quake signal after a few hours, the former can be used to follow the gain deterioration even during this huge quake. Therefore we compared all 3-d records overlapping by $2 \mathrm{~d}$ of the observed tide with a theoretical tide during the period spanned by the two calibrations. This synthetic tide for each strainmeter consisted of the body tide computed using a modified version of Longman's prediction program (Longman 1959) with Love and Shida numbers in agreement with seismological Earth models. In addition, a model for the strain-coupled local distortions was included in the synthetics (Harrison 1976). To estimate the free parameters of that model the horizontal tidal strains $\epsilon_{\theta \theta}$, $\epsilon_{\phi \phi}$ and $\epsilon_{\theta \phi}$ were computed by again using Longman's formulae and fit to the observed tidal strains from the three instruments. The regression coefficients from these fits are the sums of the trigonometric functions describing the linear strains for the particular azimuths plus an additive contribution from possible strain-straincoupling coefficients due to local heterogeneities. For the fit, two clean records were selected near the times of the two megaquakes: February 2005 and December 2010. The coupling coefficients (see Supporting Information Tables S1 and S2) from the two records are in agreement with each other and with the estimates published in Emter \& Zürn (1985). We are aware of the fact that ocean tidal loading effects were neglected in this approach. However, the effect of those small tidal signals is partially absorbed in the coupling coefficients and partially left in the residuals. A time-series of relative calibration factors and in addition real admittances of barometric pressure to strain were obtained by a least squares fit of the theoretical model and the simultaneously recorded atmospheric pressure to the observations. Fig. S2 in the Supporting Information shows the estimated gains as a function of time for the original time-series. This again demonstrates the clear loss of gain at about the time of the quake.

In a second attempt, we determine the temporal history of the instrument gain by doing a tidal analysis of a 9 month long stretch of data after this instrument had been repaired. We then extrapolated the obtained tidal model backward in time and compared it with the Tohoku data. This approach has the advantage that it implicitly contains the effect of ocean tide loading. Its disadvantage is that any non-tidal noise sources in the analysed 9-month stretch of data will degrade the tidal model. Thus the two methods are complementary in a way and since the results agree well, we have appreciable confidence in them.

These analyses indicated that the gain appeared to be nominal at the start of the record, started to decrease immediately after the Tohoku event and dropped to about 45 per cent within the initial $220 \mathrm{hr}$ (see Supporting Information Fig. S2). The pressure admittances obtained with the first method show very similar behaviour but are, of course, less stable than the calibration values. A sixth degree polynomial in time correcting the data for this gain deterioration was inversely multiplied with the time-series and the corrected series is used in Sections 5.2.2 and 5.3.2. Supporting Information Fig. S3 shows the estimated gains together with the polynomial model which describes the gain loss very well.

It is clear that this correction is by no means perfect but only approximately compensates for the loss of the gain. It has to be kept in mind that the Tohoku data for the strain in $\mathrm{N} 60^{\circ} \mathrm{E}$ and to a lesser extent the areal and shear strains have been corrected following an approximate approach. Notwithstanding this defect the spectra are of a rather high quality as will be shown in Section 5 below.

\subsection{Reduction of strain noise and tilt noise induced by atmospheric pressure variations}

At low frequencies (below $10 \mathrm{mHz}$ ) conspicuous correlations exist between local barometric pressure (outside of the airlocks) on the one hand and recorded strains and horizontal accelerations on the other hand. Translational horizontal accelerations and tilts cannot be distinguished by inertial horizontal seismometers or inertial tiltmeters (e.g. Dahlen \& Tromp 1998). Therefore we use horizontal acceleration and tilt in the following as synonyms.

Zürn et al. (2007) discuss simple models of atmospheric phenomena which cause gravity changes and deformations of the Earth and hence affect the signals. Such effects must be distinguished from instrumental effects caused by ambient air pressure variations, such as compression of the length standards (invar wires at BFO), and buoyancy effects on the tensioning mass for the strainmeters, deformation of instrument cases and base plates for the broad-band seismometers, and so forth. At BFO the effects of ambient pressure on instruments are minimized for seismic frequencies by the efficient airlock. In 2009, a second airlock was inserted into the mine tunnel providing even stronger attenuation of external pressure fluctuations in the case of the Tohoku quake.

For both models suggested by Zürn et al. (2007), the 'local deformation tilt model' (LDT) and the 'travelling wave tilt model' (TWT), the strain variations are in-phase with the local barometric pressure. Local tilts (mimicking horizontal accelerations as measured by broad-band horizontal seismometers) are in-phase with the pressure for the LDT-model, but in quadrature for the TWTmodel. Thus the tilts from the LDT-model are directly proportional to local atmospheric pressure and the tilts from the TWT-model are proportional to the Hilbert transform of that pressure. Using locally recorded barometric pressure and the above two models these authors were able to successfully reduce the noise in many horizontal seismograms with variance reductions sometimes up to 80 per cent.

The point Zürn et al. (2007) are making is that the noise in a strain record can be reduced by subtracting the scaled locally recorded barometric pressure from the data. For horizontal accelerograms, both the pressure and its Hilbert transform must be subtracted from the data, but with different scale factors. Thus we need to estimate two unknown coefficients in the case of horizontal accelerations while we only need one in the case of the strains.

To find the optimal scale factors we have carried out a grid search and optimized a penalty function consisting of the sum of the squared Fourier coefficients in the three frequency bands 0.20 $0.29,0.32-0.36$ and $0.43-0.45 \mathrm{mHz}$ (i.e. bands between the free oscillation peaks).

In Table 1, the optimal coefficients found for the three strainmeters and for the Aceh and Tohoku quake series are presented. For the corresponding horizontal accelerations in addition the coefficients for the Hilbert transform of pressure determined simultaneously are listed. The reductions in the noise levels achieved by the corrections are also given. The coefficients for the broadband seismometers may be compared with the ones found by Zürn et al. (2007; Table 2). The resulting coefficients of 0.30-0.90 $\mathrm{n} \epsilon$ $\mathrm{hPa}^{-1}$ for the strains (obtained in this section and for the spectra shown in Fig. 1) as well as the coefficients of up to $35 \mathrm{~nm} \mathrm{~s}^{-2}$ $\mathrm{hPa}^{-1}$ for the accelerograms (see Zürn et al. 2007) are physically reasonable. Considering the complexity of the atmospheric phenomena and the near-surface heterogeneities we cannot expect constant coefficients in time and space, as is almost the case for vertical accelerations. 
Table 1. Atmospheric pressure admittances to strain and horizontal accelerations determined for different earthquake records as described in Section 3.2. In the case of the horizontal accelerations, the admittances of atmospheric pressure and its Hilbert transform were determined simultaneously and the latter are given in parentheses. For the records of the two megaquakes, the percentage in noise reductions $V_{\text {red }}$ obtained by pressure corrections are also given.

\begin{tabular}{|c|c|c|c|c|c|c|c|c|}
\hline Figure & Event & Units & $\mathrm{N} 2{ }^{\circ} \mathrm{E}$ & $\mathrm{N} 60^{\circ} \mathrm{E}$ & $\mathrm{N} 300^{\circ} \mathrm{E}$ & STS-1/NS & STS-1/EW & Length (hr) \\
\hline 1 & 1994 Shikotan & $\mathrm{n} \in \mathrm{hPa}^{-1}$ & 0.50 & 0.90 & 0.75 & - & - & 64 \\
\hline 1 & 1998 Balleny Island & $\mathrm{n} \in \mathrm{hPa}^{-1}$ & 0.34 & 0.80 & 0.88 & - & - & 30 \\
\hline 1 & 2000 Wharton Basin & $\mathrm{n} \in \mathrm{hPa}^{-1}$ & 0.36 & 0.66 & 0.44 & - & - & 60 \\
\hline 1 & 2001 Peru & $\mathrm{n} \in \mathrm{hPa}^{-1}$ & 0.32 & 0.75 & 0.60 & - & - & 60 \\
\hline 4 & 2004 Aceh & $\mathrm{n} \in \mathrm{hPa}^{-1}$ & 0.47 & 0.74 & 0.69 & - & - & 220 \\
\hline 4 & & $V_{\text {red }}($ per cent) & 62 & 74 & 65 & & & \\
\hline 4 & 2004 Aceh & $\mathrm{nm} \mathrm{s}^{-2} \mathrm{hPa}^{-1}$ & - & - & - & $+33(+10)$ & $-12(-2.5)$ & 220 \\
\hline 4 & & $V_{\text {red }}($ per cent $)$ & & & & 54 & 18 & \\
\hline 5 & 2011 Tohoku & $\mathrm{n} \in \mathrm{hPa}^{-1}$ & 0.58 & 0.40 & 0.59 & - & - & 220 \\
\hline 5 & & $V_{\text {red }}($ per cent $)$ & 54 & 67 & 56 & & & \\
\hline 5 & 2011 Tohoku & $\mathrm{nm} \mathrm{s}^{-2} \mathrm{hPa}^{-1}$ & - & - & - & $+32(-22)$ & $-14(-2.0)$ & 220 \\
\hline 5 & & $V_{\text {red }}($ per cent) & & & & 44 & 5 & \\
\hline
\end{tabular}

Farrell (1972) gives the following equation for the influence of an arbitrary distribution of surface barometric pressure $P(r, \theta)$ on areal strain $\varepsilon_{a}$ on an elastic half-space:

$\varepsilon_{a}=\left(\varepsilon_{r r}+\varepsilon_{\theta \theta}\right)_{z=0}=-\frac{P(r, \theta)}{2(\lambda+\mu)}$.

$\lambda$ and $\mu$ are the Lamé parameters of the half-space, $r$ and $\theta$ are coordinates in a cylindrical coordinate system. This equation is consistent with the equations in Zürn et al. (2007) for the TWT. It is expected that areal strain is directly affected by the local pressure, while shear strains can only be produced by air pressure in the presence of lateral heterogeneities (including cavities and topography). Fig. 2 shows the dramatic reduction of areal strain noise achieved with this pressure reduction method for the 1994 Shikotan quake strain records used for Fig. 1. For the horizontal accelerograms, the improvement in SNR is less dramatic but still significant. This is illustrated in fig. 27 of Zürn et al. (2007) for the case of the N-S component recorded after the Aceh event.

\subsection{Noise in strain records}

In order to quantify the noise levels in the BFO strain observations in the long-period seismic band, we computed power spectral densities (PSDs) in a series of fourteen $48 \mathrm{hr}$ windows overlapping by 50 per cent for a largely quake-free period from 2005 March 1 to 15. During this time the highest-Q mode ${ }_{0} S_{0}$ excited by the Aceh quake was still clearly visible in the vertical accelerations recorded at BFO but not in the strainmeter records. We did this for the data from each of the three strainmeters as well as for their linear combinations (see Section 5.1 below) for areal strain and horizontal shear strain (70 windows in total). In each window and for each signal, we determined by least squares the admittance of the barometric pressure to strain and calculated residual strains. PSDs were then computed (using Hann windows) for the original and residual strain series. Then we determined the first quartile of the PSD values at each frequency for the 14 windows in each case.

Fig. 3 shows the results for the least noisy strainmeter in azimuth $\mathrm{N} 2{ }^{\circ} \mathrm{E}$ and for the areal strain both for original and pressure-corrected data. The results for the horizontal shear strain in a coordinate system rotated $45^{\circ}$ counterclockwise (ccw) with respect to the geographical one lie below the ones for the $\mathrm{N} 2{ }^{\circ} \mathrm{E}$-instrument (by a factor of two to three at $0.3 \mathrm{mHz}$ ) and are not shown. The reduction of noise with the help of barometric pressure is marginal for the
BFO - areal strain 1994 Shikotan
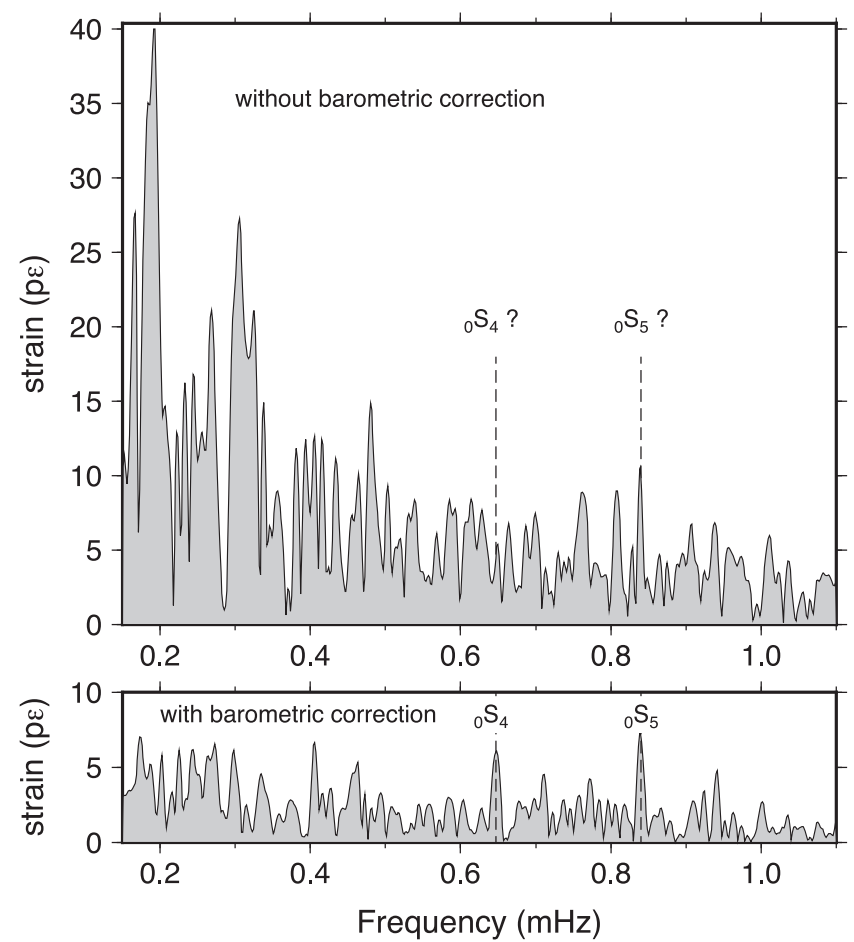

Figure 2. Spectra of the areal strain derived from the same three strain records at BFO after the Shikotan Quake in 1994 from which the shear strain in Fig. 1 was deduced. Top panel: no pressure correction applied. Bottom panel: strain records were corrected for local air pressure using the regression coefficients given in Table 1 . Modes ${ }_{0} S_{4}$ and ${ }_{0} S_{5}$ emerge from the noise after the correction.

shear strain while it is substantial for the areal strain. This makes sense if the noise is mostly caused by vertical loading of the surface. These PSDs are compared to PSDs (1. quartiles also) for linear strains observed with the NS-, EW- and NW-laser strainmeters at Piñon Flat (PFO), California, installed at the surface but optically anchored to depths of $28 \mathrm{~m}$ (Barbour \& Agnew 2011, data kindly provided by D.C. Agnew). The PSDs for the raw data from the best BFO strainmeter and the areal strain clearly lie below the PSDs from PFO. Pressure correction improves on this already favourable condition for frequencies below about $2 \mathrm{mHz}$. Of course, linear, areal and 


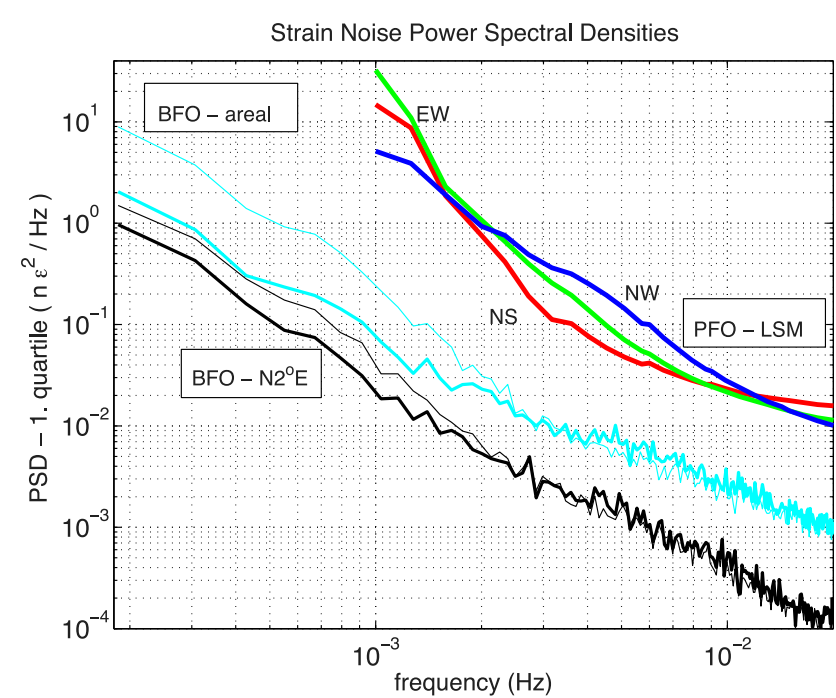

Figure 3. First quartile (25 per cent) of PSDs for the best linear strainmeter at $\mathrm{BFO}\left(\mathrm{N} 2^{\circ} \mathrm{E}\right.$, black) and areal strain (cyan). Thin line is for original, and thicker line is for pressure-corrected data. The red, green and blue lines are the 1st quartile of the PSDs for the linear strains (LSM) at PFO in 2009 (courtesy of D.C. Agnew).

shear strains should not be compared without some reservations but we do this here due to the lack of a reference PSD for the latter two variables. Not surprisingly the PSD for areal strain noise is clearly higher than for our best linear strainmeter. The variance reductions for the 70 windows are between 22 and 99.5 per cent with a mean value of 81 per cent. The range of barometric admittances to linear strain obtained for the total of $702-\mathrm{d}$ windows is between -0.14 and $2.12 \mathrm{n} \epsilon \mathrm{hPa}^{-1}$ with the mean at $0.49 \mathrm{n} \epsilon \mathrm{hPa}^{-1}$, positive sign corresponding to rock dilatation with increasing pressure. A negative coefficient is not consistent with pressure loading and probably rather indicates the uncertainty of the admittance estimates. Using eq. (1) and letting $\lambda=\mu$ we obtain an effective shear modulus $\mu$ of $50 \mathrm{GPa}$ for the crust for pressure loading, which is a realistic order of magnitude.

\section{SYNTHETIC SEISMOGRAMS}

The Higher Order Perturbation Theory (HOPT) method of Lognonné \& Clévédé (2002) was used to compute realistic ultralowfrequency $(f \leq 1 \mathrm{mHz})$ synthetic acceleration and strain seismograms taking into account rotation and ellipticity, for the anelastic 1-D Earth model PREM (Dziewonski \& Anderson 1981). Specifically, normal mode eigenfrequencies and eigenfunctions are determined for PREM. In the non-dispersive approximation, perturbations up to the third order in frequency due to Earth's rotation and ellipticity of figure are then added using the exact formulation described by Dahlen \& Tromp (1998). Full coupling between different modes is included up to $1 \mathrm{mHz}$; interaction matrices are calculated following the theory developed by Woodhouse \& Dahlen (1978) and, for each coupling matrix, its Frobenius norm is calculated, which characterizes the coupling strengths between modes. In order to speed up our calculations, we only use modes which are significantly coupled, using the Frobenius norm as criterion. We then compute receiver modulation functions for each station and source modulation functions for each earthquake and then combine them to obtain the synthetic seismograms (Clévédé \& Lognonné 1996).
Synthetic acceleration and strain spectra are compared to observed spectra for the Aceh quake and the Tohoku event in the following section and in the Supporting Information. We applied a Fourier transform to the $220 \mathrm{hr}$ long synthetics after multiplication by a Hann window the same way as with the observations. The earthquake source models used to calculate the synthetics are the 5-point model of Tsai et al. (2005) for Aceh and the GCMT solution (Global Centroid Moment Tensor; Ekström: www.globalcmt.org; Dziewonski et al. 1981) for the Tohoku quake. The vertical acceleration spectra are compared to corresponding synthetics in Figs A1 and A2 in Appendix A.

We used HOPT to calculate theoretical displacements for a $100 \mathrm{~m}$ spacing array around BFO, which were used to compute the strain tensor components in a spherical coordinate system. Since the HOPT code is set up to compute synthetic seismograms for inertial sensors we had to take care first that the contributions of tilts and gravitational potential changes were removed from the computed accelerations before integrating those to get displacements. The equivalent of eq. (2) below was used to compute the strain synthetics to be compared with the observed strain components.

These raw synthetic strain spectra are compared to the observed strain spectra in Figs S4 and S5 in the Supporting Information. Since it is known from earlier Earth tide analyses of records from the BFO strainmeters that local distortions of the strain fields occur, we used coupling coefficients determined again from recent tidal records as described in Section 3.3.1, the Supporting Information and listed in Table S1 to modify the synthetic strains (as also done by Park et al. 2008). We obtained overall reductions of the misfits and therefore in Figs 4-7 the strain synthetics include these local distortions of the large scale strain field caused by cavities, topography and rock heterogeneities (in the following called 'cavity effects' for short; Harrison 1976).

\section{COMPARISON OF OBSERVATIONS WITH SYNTHETICS}

\subsection{Linear, areal and shear strains}

The response of a horizontal linear strainmeter of length $l_{0}$ and sensor azimuth $\psi$ (measured from $\mathrm{N}$ to E) is (e.g. Turcotte \& Schubert 1982):

$\frac{\delta l}{l_{0}}(\psi)=\varepsilon_{\theta \theta} \cdot \cos ^{2}(\psi)+\varepsilon_{\phi \phi} \cdot \sin ^{2}(\psi)-\varepsilon_{\theta \phi} \cdot \sin (2 \psi)$,

where $\theta$ and $\phi$ are the coordinates of a spherical coordinate system with the $\theta$-axis oriented towards the South Pole and the $\phi$-axis pointing East. At BFO there are three similar strainmeters of length $l_{0}=10 \mathrm{~m}$ and with $\psi$ equal to $2^{\circ}, 60^{\circ}$ and $300^{\circ}$.

These angles constitute a nearly $120^{\circ}$-array and if the calibrated signals of the three instruments of such an array are simply added one obtains the areal strain in very good approximation:

$\frac{\delta A}{A_{0}}=\frac{2}{3} \cdot\left[\frac{\delta l}{l_{0}}\left(2^{\circ}\right)+\frac{\delta l}{l_{0}}\left(60^{\circ}\right)+\frac{\delta l}{l_{0}}\left(300^{\circ}\right)\right]$.

The approximations consist of (1) a small deviation $\left(2^{\circ}\right)$ of one of the devices from the $120^{\circ}$ configuration, (2) the spatial separation of the three instruments of mutually about $50 \mathrm{~m}$ and (3) the possibility of differently disturbed amplitudes due to local elastic effects caused by cavities, topography and inhomogeneous geology (Harrison 1976).

To find the angle $\xi$ for which the spectral SNR for the toroidal modes is a maximum we essentially rotate the local coordinate 
BFO - Aceh 2004
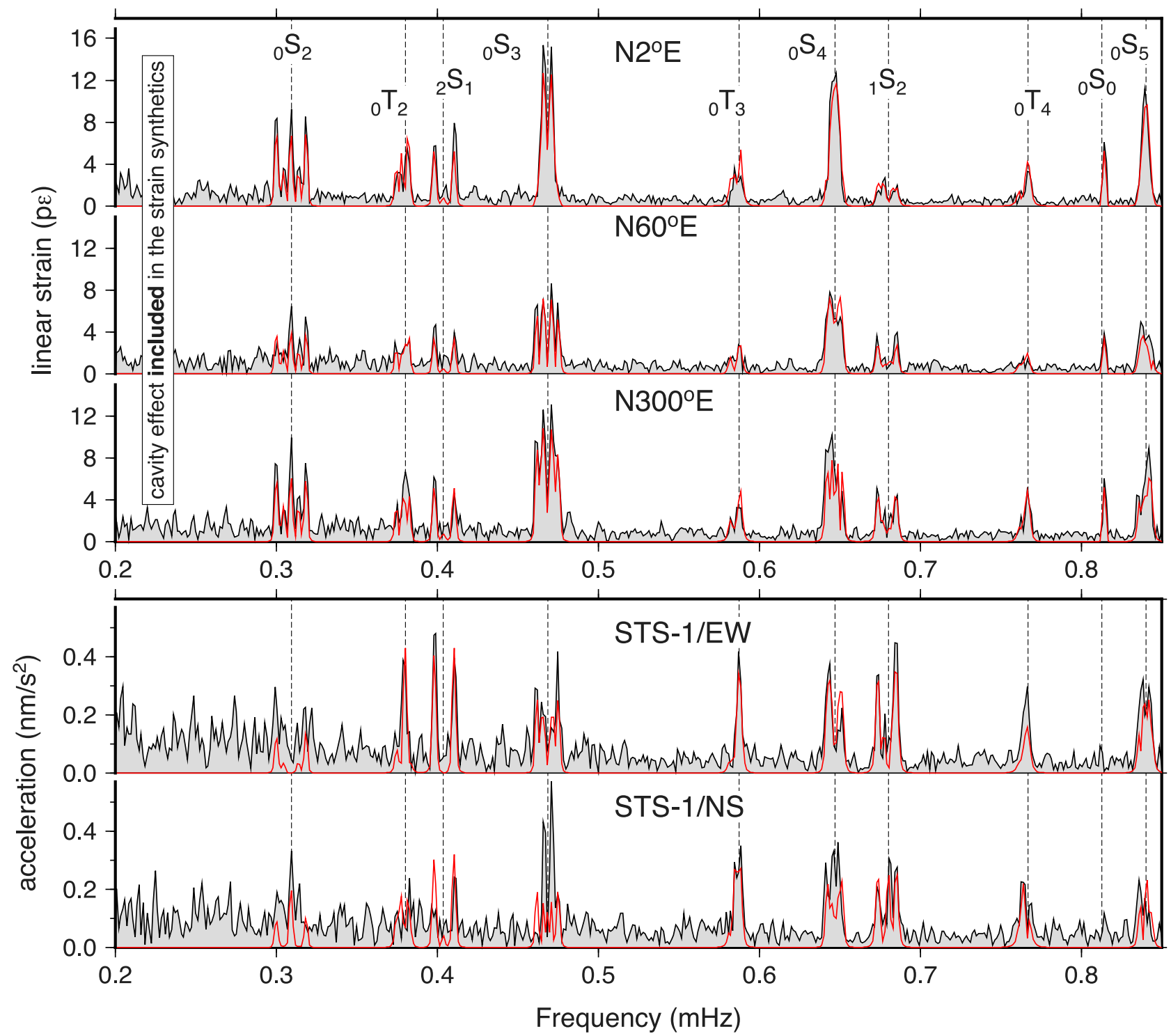

Figure 4. Spectra of $220 \mathrm{hr}$ time-series from the invar-wire strainmeters and horizontal STS-1 broad-band seismometers (black) at BFO after the Aceh quake and corresponding synthetics (red) including the cavity effects for the strains. Time-series start at 2:30:00.0 hr UTC on 2004 December 26. Data were calibrated, instrument corrected, detided, corrected for air pressure effects and multiplied by a Hann taper before the Fourier transform. The calibrated pressure was multiplied by the factors given in Table 1 and subtracted from the strainmeter records and seismograms. In addition, the Hilbert transform of the pressure was subtracted from the seismograms using factors also given in Table 1. The resulting variance reductions are listed in Table 1 as well. Instrument orientations are listed in the panels. Dashed vertical lines represent degenerate multiplet frequencies from model 1066A (Gilbert \& Dziewonski 1975).

system with respect to the geographical one by adding a constant angle $\xi$ to each of the strainmeter azimuths $\psi$. Then we have three eqs (2), one for each strainmeter, with which we can solve for the shear component in this new coordinate system. A positive angle $\xi$ rotates the coordinate system in a counter-clockwise direction. The coordinate axes for which the shear strain component vanishes are the principal axes of the strain tensor.

In the next subsections, we first compare spectra of timeseries from the linear strainmeters and the broad-band horizontal STS-1 seismometer records as well as the corresponding synthetics after the Aceh and Tohoku events and then areal and shear strains derived from the linear strainmeter records. The lengths of the time-series, $220 \mathrm{hr}$, are optimized for ${ }_{0} S_{2}$ singlet resolution and SNR when a Hann taper is applied before the FFT.

\subsection{Linear strain versus horizontal acceleration}

Before comparing the spectra from strain and acceleration seismograms we refer the reader to Appendix A, where we compare the spectra of the vertical accelerograms from BFO for the Aceh (Fig. A1) and Tohoku (Fig. A2) quakes with the corresponding synthetics. In both cases, the amplitudes and splitting of the observed spectra are predicted very well by our synthetic spectra. This demonstrates that the earthquake source models and the forward modelling scheme used are accurate, capturing the dominant signals in the low-frequency vertical acceleration spectra.

Figs 4 and 5 depict spectra of $220 \mathrm{hr}$ long time-series of the three strainmeters and the EW- and NS-component STS-1 broadband seismometers obtained after the Aceh and Tohoku quakes, respectively. We point out first that in the frequency band of the 
BFO - Tohoku 2011
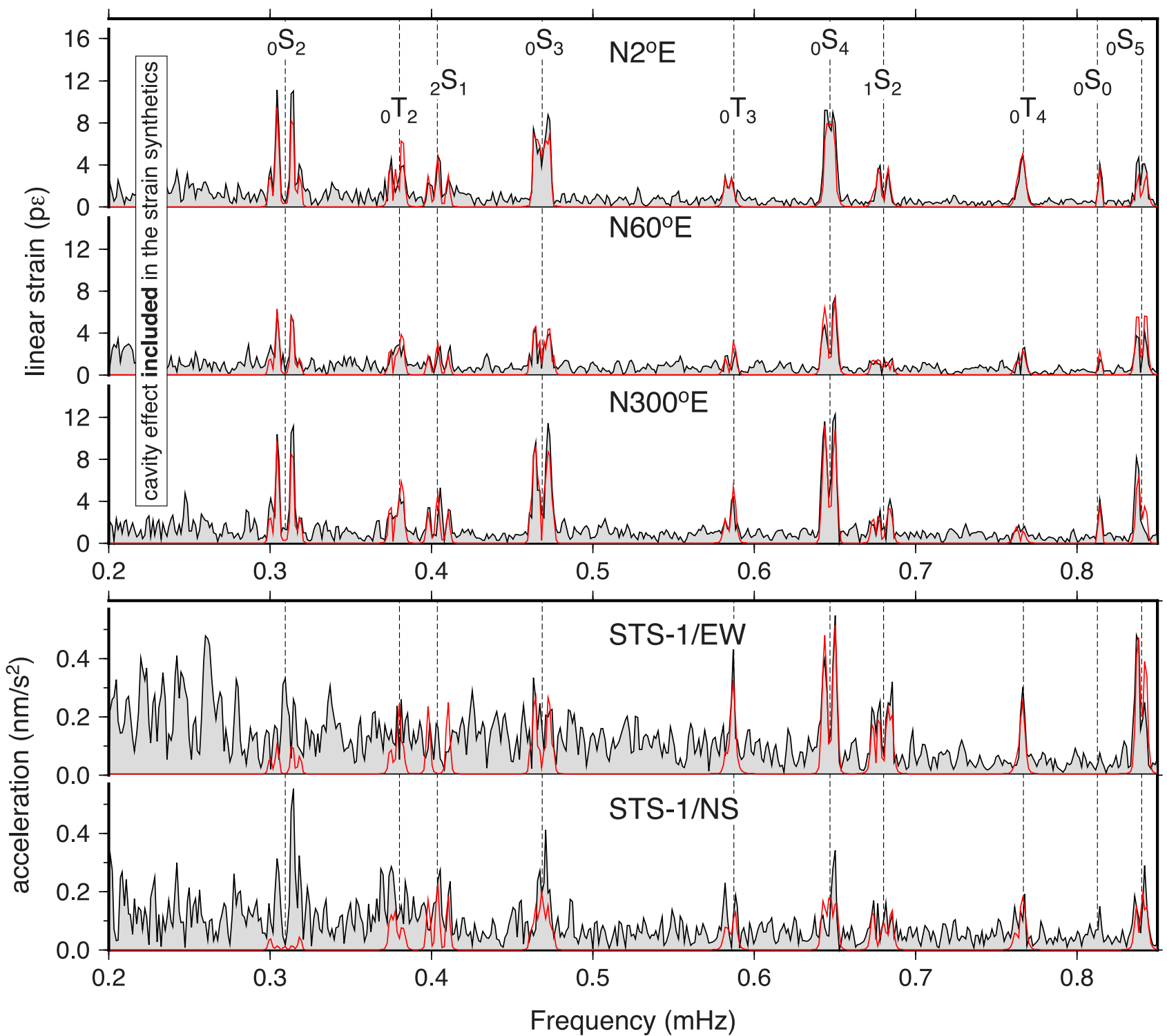

Figure 5. Same as Fig. 4 after the Tohoku quake. Time-series start at 6:45:00.0 UTC on 2011 March 11. The calibrated pressure was multiplied by the factors given in Table 1 and subtracted from the strain records and accelerograms. In addition, the Hilbert transform of the pressure was subtracted from the seismograms using factors also given in Table 1 . The resulting variance reductions from the pressure corrections are listed as well in Table 1.

normal modes the STS-1 broad-band seismometers at BFO and especially the horizontal ones are acknowledged by seismologists to be performing among the best ones of the GSN (Berger et al. $2004)$ in the frequency band of the normal modes. Kurrle \& WidmerSchnidrig (2008) used the data from the STS-1/EW-seismometer at BFO for their discovery of the toroidal and spheroidal horizontal background oscillations (horizontal 'Hum'). Although the Hum is seen at frequencies above $2 \mathrm{mHz}$ its observation still demonstrates the high quality of these horizontal seismograms from BFO.

\subsubsection{Aceh quake}

For the Aceh quake (Fig. 4), all five singlets of ${ }_{0} S_{2}$ are resolved in the strains while at most one of them can be barely identified in the NS-acceleration. The $m= \pm 1$ singlets are much smaller than the other three. Overall, the synthetics slightly underpredict the observed amplitudes. Clearly at this frequency the SNR of the strainmeters is superior to both horizontal seismometers, even in the case of the $\mathrm{N} 60^{\circ}$ E-strain with the smallest SNR. In the frequency range up to $0.85 \mathrm{mHz}$, the SNR even for the worst strainmeter is better than for the horizontal accelerograms.

The mode ${ }_{0} T_{2}$ can be identified both in the three strains and the EW-acceleration and it is visibly split in the top panel. To our knowledge this is the first single record in which the splitting of ${ }_{0} T_{2}$ can be identified directly, while all the singlets have been resolved by stripping methods using a multitude of seismograms and earthquakes (Laske, personal communication, 1992). The amplitude is well predicted by the synthetics except for the $\mathrm{N} 300^{\circ}$ E-instrument.

In the case of widely split ${ }_{2} S_{1}$ two $(m= \pm 1)$ of the three singlets can be identified in all strains and the EW-acceleration, only one of them in the NS-acceleration. In all cases, the predictions are reasonably good given the low SNR. 


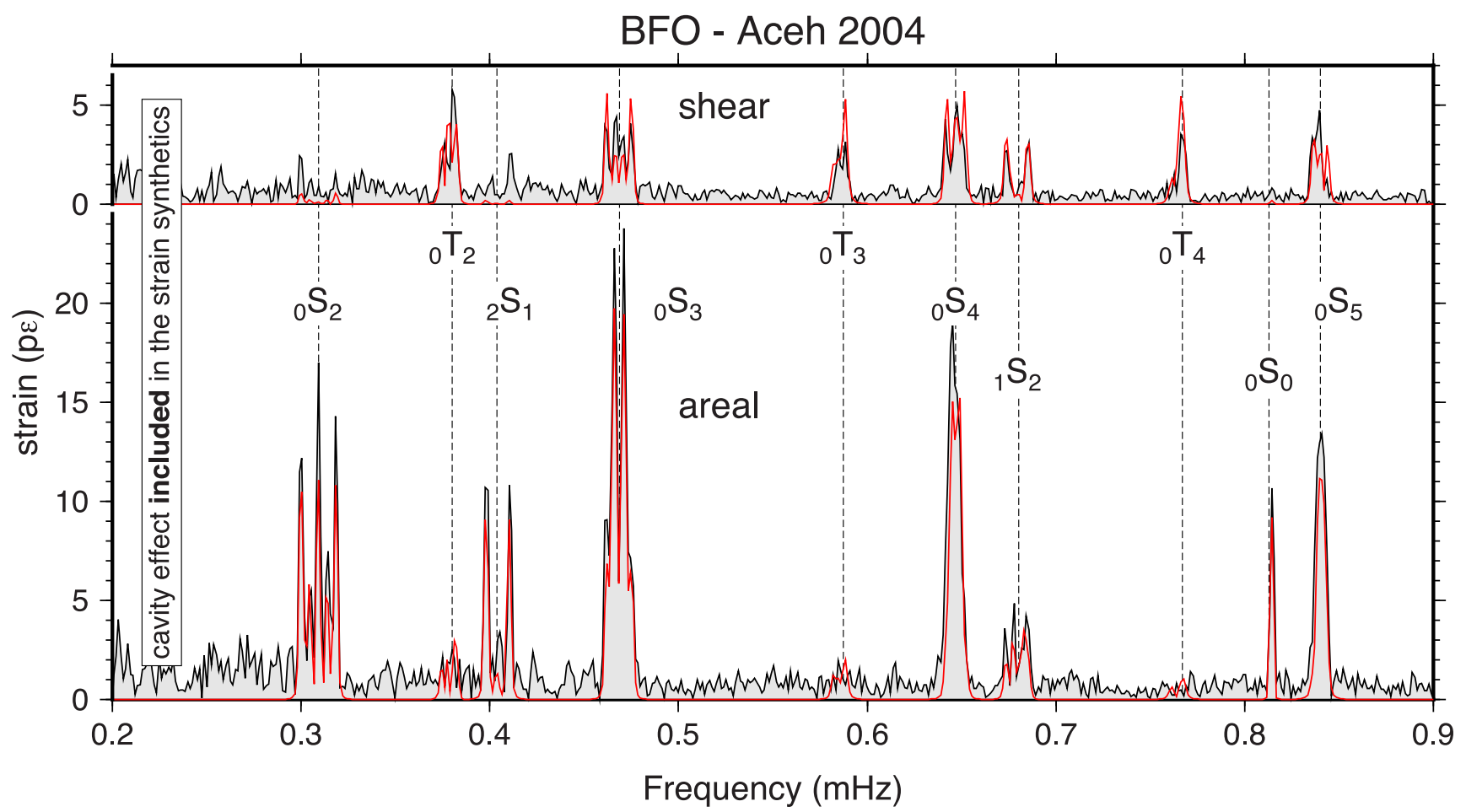

Figure 6. Spectra of two combinations of the linear strain data from the BFO strainmeters (black) and corresponding synthetics including the cavity effect (red) after the Aceh quake: shear strain (top) and areal strain (bottom). To calculate the shear strain, we rotated the coordinate system by $65^{\circ} \mathrm{ccw}$. Dashed vertical lines are located at the multiplet frequencies from model 1066A from Gilbert \& Dziewonski (1975). All toroidal mode peaks are essentially absent in the areal strain spectrum. The relative amplitudes of spheroidal modes relative to the toroidal ones have strongly decreased in the shear strain. Especially ${ }_{0} S_{0}$ has disappeared from the shear strain, while it has very good SNR in the areal strain spectrum.

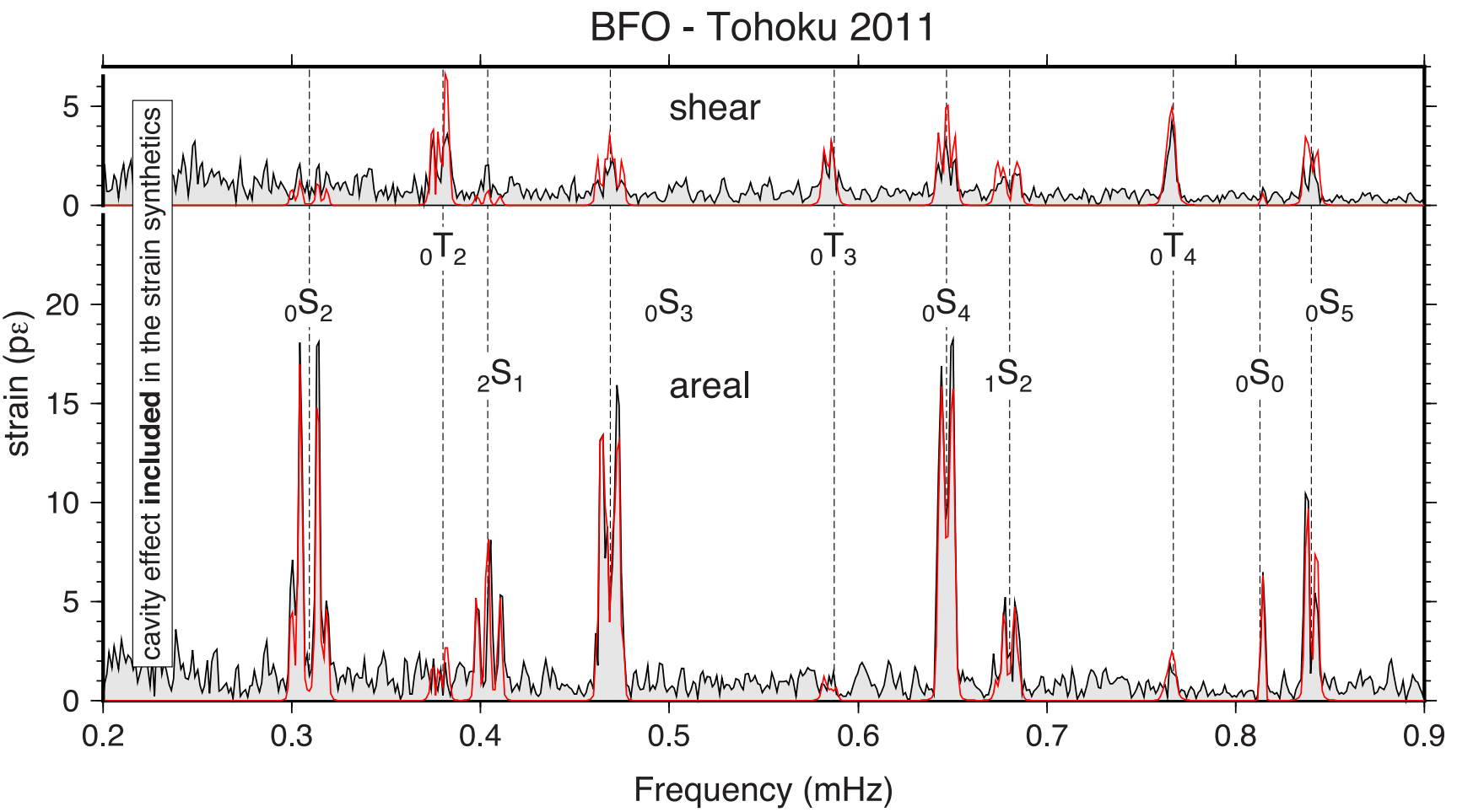

Figure 7. Same as Fig. 6 after the Tohoku quake: shear strain (top) and areal strain (bottom). To calculate the shear strain, we rotated the coordinate system by $45^{\circ} \mathrm{ccw}$. Again the toroidal modes have essentially disappeared from the areal strain spectrum (a residual of ${ }_{0} T_{4}$ may still be identified), while they are enhanced relative to the spheroidal ones in the shear strain spectrum. Radial mode ${ }_{0} S_{0}$, prominent in the areal strain, has disappeared from the shear strain. The toroidal modes ${ }_{0} T_{2}$ and ${ }_{0} T_{3}$ are clearly split. 
The mode ${ }_{0} S_{3}$ shows splitting in essentially all components, but not all seven singlets can be resolved with the $220 \mathrm{hr}$ records. The predicted spectral shape and amplitude fit reasonably well for all components with the exception of the NS-acceleration, where the inner singlets are conspicuously underpredicted in contrast to the outer singlets which are somewhat overpredicted. From earlier studies by Zürn \& Emter (1995), Lambotte et al. (2006b) and Lambotte (2007), it is known that the STS-1/NS seismometer at BFO is influenced by a strong cavity effect enhancing for example tidal tilts by a factor of about 2 . This could easily be one of the reasons for the observed enhancement of the inner singlets of this mode compared with the synthetics. In Appendix B, we show that the spectral line shapes for modes with appreciable tilt contributions to the signal obtained from different inertial horizontal sensors installed less than $100 \mathrm{~m}$ apart in the mine differ considerably. These differences in the observed spectra can possibly be explained by 'cavity effects'.

Toroidal mode ${ }_{0} T_{3}$ has relatively low amplitude and is well predicted in all five cases. This mode is observed at higher SNR in the acceleration spectra.

The overall amplitudes of ${ }_{0} S_{4}$ are relatively well predicted. However, there are some discrepancies in the shapes of the only partially resolved multiplet.

The overtone ${ }_{1} S_{2}$ also shows splitting in essentially all components. The predicted amplitudes compare well to the observed ones.

Toroidal mode ${ }_{0} T_{4}$ is very well predicted except for the EWacceleration, where the observed amplitude is nearly twice as large as the theoretical one. Especially the differing amplitudes for the strainmeters are well reproduced by the synthetics.

The radial fundamental mode ${ }_{0} S_{0}$ is identified with good SNR in all three strain records, while it is completely absent in the horizontal accelerations as it ought to be. We discuss the ${ }_{0} S_{0}$ observation in more detail in Section 6 below. The predicted amplitudes are equal for the three strainmeters but the observed ones are not. Especially for the $\mathrm{N} 60^{\circ} \mathrm{E}$-strain the observed amplitude is about half of the theoretical one without the cavity effect, but when this is included it fits very well.

Overall the amplitudes of ${ }_{0} S_{5}$ are fairly well predicted, for all components with only small discrepancies in spectral shape.

It appears that the SNR near ${ }_{0} S_{2}$ is clearly better for the strain records while it is still slightly better up to $0.85 \mathrm{mHz}$. Of course, these conclusions must be taken with a grain of salt, since we compare spectra of different observables with each other and because orientations of the instruments, source properties, distance to the source and back-azimuth all have an influence on the signal amplitude and consequently SNRs. Barbour \& Agnew (2012) present a more rigorous comparison of noise levels of seismometers and strainmeters which is only possible if the phase velocities of the seismic phenomena responsible for the noise are known.

\subsubsection{Tohoku quake}

In the case of the Tohoku quake (Fig. 5), we have to keep in mind that the record for the $\mathrm{N} 60^{\circ} \mathrm{E}$-strainmeter was corrected in an approximate way for the time variable loss in gain (Section 3.1.1)

For ${ }_{0} S_{2}$, the $m= \pm 1$ singlets are very strong in the three strain spectra, while $m=0$ is missing in all spectra, except for the EWacceleration, where a noise peak happens to appear at the frequency of the $m=0$ singlet. One singlet only is observed in the NSacceleration $(m=+1)$. The predicted spectra compare well in shape with the ones derived from observations for the strainmeters, but predicted amplitudes are somewhat smaller for the strains. If the only singlet observed in the NS-acceleration is real, which its SNR suggests, it is much larger than the predicted one. This is probably due to a 'cavity effect' again.

The split multiplet ${ }_{0} T_{2}$ can be identified only in the strains but with less SNR than for Aceh. On the other hand nothing appears above the noise in the acceleration spectra. Predictions fit the observed peaks rather well.

This situation repeats for the three singlets of ${ }_{2} S_{1}$ with the strain data clearly showing larger SNR than the accelerations. The predictions are reasonably good. The elusive $\mathrm{m}=0$ singlet of this mode is observed with rather high SNR here.

The mode ${ }_{0} S_{3}$ is clearly observed in the strain and NSacceleration spectra, while in the EW-acceleration it is buried in the noise. Again the SNR for the strain records is much better than for the accelerations. In the $\mathrm{N} 60^{\circ} \mathrm{E}$-spectrum, the SNR is really good despite the problem of decreasing gain in the record.

Toroidal mode ${ }_{0} T_{3}$ is observable in all spectra except the $\mathrm{N} 60^{\circ} \mathrm{E}-$ strain. In this case, the EW-acceleration has a good SNR. The predictions reproduce the observations rather well when the SNR is taken into consideration.

The mode ${ }_{0} S_{4}$ has good SNR again and is well predicted in spectral shape and amplitude for all three strains and EW-acceleration in spectral shape and amplitude. The NS-acceleration has larger amplitude than predicted which could be due to an enhancement by the cavity effect. The SNR is clearly better for the strainmeters than for the seismometers.

The SNR for ${ }_{1} S_{2}$ is not really high in all five spectra, except maybe for the $\mathrm{N} 2{ }^{\circ} \mathrm{E}$-strain. Considering this the agreement between observations and predictions is rather good, especially the splitting is well reproduced by theory.

Toroidal mode ${ }_{0} T_{4}$ is observed with good and similar SNR only for $\mathrm{N} 2{ }^{\circ} \mathrm{E}$-strain and $\mathrm{EW}$-acceleration, while hints of it can be seen for NS-acceleration and for $\mathrm{N} 60^{\circ} \mathrm{E}$-strain. In the $\mathrm{N} 300^{\circ} \mathrm{E}$-strain, it is very small and swamped by noise. Where SNR is high the predictions are fairly good.

The fundamental radial mode ${ }_{0} S_{0}$ appears again very clearly in the spectra with good SNR for $\mathrm{N} 2{ }^{\circ} \mathrm{E}$ - and $\mathrm{N} 300^{\circ} \mathrm{E}$-strain. It is not clearly above the noise for the $\mathrm{N} 60^{\circ} \mathrm{E}$-strain, but this apparent amplitude seems well predicted. The fact that it is smaller in this component as compared to the others again must be blamed to the strong cavity effect on this instrument (see Supporting Information Tables S1 and S2). This cannot be blamed to possible deficiencies of our modification due to calibrations, since these would not affect the SNR if the noise is caused by strains (e.g. uncompensated meteorological noise). However, if a substantial part of the noise is instrumental a drop in the gain of the strainmeter would cause a deterioration of the SNR. Unexpectedly the NS-acceleration spectrum shows a small peak very near the frequency of ${ }_{0} S_{0}$. Fichler-Fettig et al. (1986) predicted this effect for the case when strong cavity effects exist: strains cause tilts which show up in horizontal accelerograms.

For ${ }_{0} S_{5}$, again in some cases, the predicted spectral shapes differ somewhat from the observed ones. Overall amplitudes agree fairly well for both accelerations components, while for $\mathrm{N} 2^{\circ} \mathrm{E}$ - and $\mathrm{N} 60^{\circ}$ E-strain theory predicts amplitudes which are too small and too large, respectively.

Although the information contained in the areal and shear strain spectra is not independent of the linear strains above we still discuss them in the next subsection. One advantage of inspecting areal and shear strains is that toroidal modes should disappear for the areal 
strain and appear enhanced relative to the spheroidal modes in the shear strains.

\subsection{Areal versus shear strain}

From the three linear strain records prepared as described in Section 5.1 above, we can calculate the areal strain and horizontal shear strains (in a rotated coordinate system) as described in Section 5.1.

\subsubsection{Aceh quake}

For the Aceh quake shear strain records, we found the best angle of rotation to be near $65^{\circ}$ for the toroidal modes ${ }_{0} T_{2},{ }_{0} T_{3}$ and ${ }_{0} T_{4}$. In Fig. 6 (bottom), we depict the spectrum of $220 \mathrm{hr}$ following the Aceh quake of the areal strain computed from the three individual linear strains following eq. (3). All toroidal modes have disappeared in the areal strain spectrum while the spheroidal modes stand out more clearly when compared with the linear strain spectra. However, small peaks appear at the frequencies of the toroidal modes in the synthetic spectra. We interpret this as the small effect of Coriolis coupling (Zürn et al. 2000) which becomes visible in the noise - free synthetics. We also combined the three records to obtain the shear strain and show its spectrum in Fig. 6 (top). Compared to the linear strain spectra the toroidal modes appear enhanced with respect to the spheroidal modes.

All five singlets of ${ }_{0} S_{2}$ are resolved and stand clearly above the noise floor in the areal strain while they have essentially disappeared in the observed shear strain, except possibly for a hardly significant little peak for singlet $m=-2$. All the predicted singlet amplitudes are too small by about 25 per cent.

The mode ${ }_{0} T_{2}$ is clearly split in two and the modes ${ }_{0} T_{3}$ and ${ }_{0} T_{4}$ have good SNR and are very well predicted by the synthetics in the shear strain.

The singlets $m= \pm 1$ of ${ }_{2} S_{1}$ are very clear and well predicted by the theory, while the $m=0$ singlet has low SNR, in the areal strain. The $m=+1$ singlet is unexpectedly visible above the noise in the shear strain.

The mode ${ }_{0} S_{3}$ is much better predicted by the synthetics with the cavity effect included than without. Observed areal strains for this mode are still about 15 per cent larger than the predicted ones. The shear strains are rather well predicted. The situation for ${ }_{0} S_{4}$ is very similar.

The mode ${ }_{1} S_{2}$ clearly shows splitting; it is slightly underpredicted in the areal, but very well predicted in the shear strain.

Mode ${ }_{0} S_{0}$ is missing in the shear strain as predicted and slightly underpredicted in the areal strain.

The mode ${ }_{0} S_{5}$ is well predicted in the shear strain. For the areal strain, the predicted amplitude is about 85 per cent of the observed. So there is similar agreement between observations and predictions for ${ }_{0} S_{3},{ }_{0} S_{4}$ and ${ }_{0} S_{5}$.

To conclude the discussion of the shear strain spectrum we note that it compares favourably in quality with the spectrum of $90 \mathrm{hr}$ of data from the two laser strainmeters at Gran Sasso, Italy (Park et al. 2008; Fig. 3).

\subsubsection{Tohoku quake}

For the Tohoku quake strain records, we found the best angle of rotation (in terms of SNR) to be near $45^{\circ}$ for the toroidal modes ${ }_{0} T_{2}$ and $80^{\circ}$ for modes ${ }_{0} T_{3}$ and ${ }_{0} T_{4}$. Since the observation of ${ }_{0} T_{2}$ is the most important one we chose the angle $45^{\circ}$ to solve for the shear strain and the SNRs for ${ }_{0} T_{3}$ and ${ }_{0} T_{4}$ are still pretty good. In Fig. 7, we compare the spectra of the calculated areal strain (bottom) and the shear strain (top) in a coordinate system rotated $45^{\circ} \mathrm{ccw}$ with respect to the geographical one for the $220 \mathrm{hr}$ records after the Tohoku quake. We remind that one of the strain recordings has been corrected for a time dependent gain in an approximate way and hence we have to be careful with conclusions.

As expected the toroidal modes have disappeared from the areal strain with the possible exception of ${ }_{0} T_{4}$. All spheroidal modes are clearly split with the exception of $S_{0}$, which again has a high SNR. Again in the noise-free predicted spectrum of the areal strain small peaks appear at the fundamental toroidal mode frequencies which we believe to be due to Coriolis coupling. The spheroidal modes are reduced in the shear strain spectrum with respect to the toroidal modes.

The gravest mode ${ }_{0} S_{2}$ is well predicted in shape by the synthetics for the areal strain, however the predicted amplitudes are a little too small. In the shear strain spectrum it is not above the noise.

Modes ${ }_{0} T_{2}$ and ${ }_{0} T_{3}$ are visibly split in the shear strain spectrum and rather well predicted. All three singlets of rarely observed ${ }_{2} S_{1}$ stand out well above the noise in the areal strain and are well predicted also. This observation alone is an achievement which must be emphasized since the $m=0$ singlet has been very elusive up to this quake and is also missing in the vertical accelerations from this quake. This mode is essentially missing in the shear strain.

The modes ${ }_{0} S_{3}$ and ${ }_{0} S_{4}$ show very similar behaviour as after the Aceh event with slight underprediction in amplitude.

The mode ${ }_{1} S_{2}$ is almost in the noise in the shear spectrum, however has fair SNR, is visibly split and rather well predicted in the areal strain spectrum.

Radial mode ${ }_{0} S_{0}$ has good SNR in the areal strain and has disappeared in the shear strain.

The mode $S_{0}$ is split and rather well predicted in the areal strain, while it is overpredicted in the shear strain spectrum.

The SNRs in these spectra are excellent compared to the spectra obtained with two of the top-notch broad-band horizontal STS1 seismometers at BFO. Admittedly the modes shown here are all located in frequency below the passband of the seismometers. Since good observations of these long-period modes in horizontal components are rare it is worthwhile to exploit the available strain records. Barbour \& Agnew (2011) compared noise levels of the borehole strainmeters of the Plate Boundary Observatory (PBO) in Southern California with each other, but also with other strainmeters including the ones at BFO. It appears from their study that the PBO strainmeters have higher noise levels in the normal mode frequency band than those at BFO, and, to our knowledge, no normal mode spectra based on PBO strainmeter data have been published yet.

\section{BREATHING MODE ${ }_{0} S_{0}$}

For a non-rotating laterally homogeneous spherical Earth with radius $R_{\mathrm{E}}$, a simple geometrical relation exists between the radial displacement amplitude $u_{\mathrm{r}}$ of $S_{0} S_{0}$ and the linear strain in any azimuth $\epsilon_{\psi}$ measured by a horizontal linear strainmeter (both measured at the surface):

$\epsilon_{\psi}\left({ }_{0} S_{0}\right)=\frac{\delta l}{l_{0}}=\frac{\delta R_{\mathrm{E}}}{R_{\mathrm{E}}}=\frac{u_{\mathrm{r}}}{R_{\mathrm{E}}}$.

This relation holds for any radial mode ${ }_{n} S_{0}$, at any instant of time, at any point on the surface, and independent of the strainmeter's 
Table 2. Estimates of Earth's radius $\tilde{R}_{\mathrm{E}}$ from the radial acceleration and strain amplitudes of ${ }_{0} S_{0}$ observed at $\mathrm{BFO}$ after the Aceh quake. The ratio of $\tilde{R}_{\mathrm{E}}$ to the mean Earth radius of PREM $(a=6371 \mathrm{~km})$ is given in the last column. The upper part of the table uses the raw strain amplitudes, in the lower part these amplitudes were corrected for strain-strain coupling. These estimates only show that strain and gravity amplitudes are consistent. ET-19 is the LaCoste-Romberg Earth Tide Gravimeter at BFO (Richter et al. 1995).

\begin{tabular}{lcccc}
\hline Instrument & Amplitude of ${ }_{0} S_{0}$ & Units & $\begin{array}{c}\tilde{R}_{\mathrm{E}} \\
(\mathrm{km})\end{array}$ & $\tilde{R}_{\mathrm{E}} / a$ \\
\hline ET-19 & 1.49 & $\mathrm{~nm} \mathrm{~s}{ }^{-2}$ & - & - \\
$\mathrm{St}-0\left(\mathrm{~N} 2{ }^{\circ} \mathrm{E}\right)$ & 8.35 & $\mathrm{p} \varepsilon$ & 6111 & 0.96 \\
$\mathrm{St}-3\left(\mathrm{~N} 300^{\circ} \mathrm{E}\right)$ & 9.51 & $\mathrm{p} \varepsilon$ & 5364 & 0.84 \\
$\mathrm{St}^{-4}\left(\mathrm{~N} 60^{\circ} \mathrm{E}\right)$ & 8.00 & $\mathrm{p} \varepsilon$ & 6378 & 1.00 \\
$\varepsilon_{a}($ areal $)$ & 14.12 & $\mathrm{p} \varepsilon$ & 7099 & 1.11 \\
\hline St-0 $\left(\mathrm{N} 2{ }^{\circ} \mathrm{E}\right)$ & 8.79 & $\mathrm{p} \varepsilon$ & 5805 & 0.91 \\
St-3 $\left(\mathrm{N} 300^{\circ} \mathrm{E}\right)$ & 11.19 & $\mathrm{p} \varepsilon$ & 4559 & 0.72 \\
St-4 $\left(\mathrm{N} 60^{\circ} \mathrm{E}\right)$ & 13.79 & $\mathrm{p} \varepsilon$ & 3700 & 0.58 \\
\hline
\end{tabular}

azimuth. The change in length of the strainmeter $\delta l$ is equal to the radial displacement amplitude multiplied by the (very small) ratio of the length $l_{0}$ of the strainmeter over Earth's radius. Simply put, the relative change in Earth's circumference is equal to the relative change in Earth's radius. The corresponding areal strain amplitude $\epsilon_{a}\left({ }_{0} S_{0}\right)$ would be $2 \cdot \epsilon_{\psi}$ and the dilatation amplitude $\epsilon_{v}$ measured by volumetric strainmeters would be:

$\epsilon_{v}\left({ }_{0} S_{0}\right)=2 \cdot \frac{1-2 v}{1-v} \cdot \epsilon_{\psi}\left({ }_{0} S_{0}\right)$,

where $v$ is the Poisson ratio of the rocks near the surface.

The displacement $u_{\mathrm{r}}$ can be estimated using data from a vertical accelerometer (for the spherical Earth the two instruments do not even have to be collocated). However, for the estimation of the radial displacement amplitude at the low frequency $f_{0}\left({ }_{0} S_{0}\right)=0.8145 \mathrm{mHz}$ one has to take into account the contributions of the free air effect and the inertial effect (e.g. Dahlen \& Tromp 1998, eq. 10.71; Zürn $\&$ Wielandt 2007). The vertical gravity gradient in the vault, where the gravimeter is operated, is only about two thirds of the free air gradient, however, since the rocks move with the sensor the free air gradient must be used here. This leads to an estimate of the Earth's radius:

$\tilde{R}_{\mathrm{E}}=\frac{a_{r} \cdot l_{0}}{\delta l_{0}\left[4 \pi^{2} f_{0}^{2}+\left|\frac{\Delta g}{\Delta r}\right|\right]}$

where $a_{r}$ is the observed vertical acceleration amplitude and the second term in the denominator is the vertical gravity gradient. The free air effect is on the order of 10 per cent of the total acceleration signal, a substantial contribution. We do not suggest to get a precise value for the Earth's radius here, however, with this relationship we can check the consistency of the measured amplitudes. We estimated the initial amplitudes of gravity and strains by fitting to the narrowly bandpass filtered time-series decaying sinusoids and cosinusoids with the known eigenfrequency and $Q$ of ${ }_{0} S_{0}$. For gravity, we used a 36-d time-series obtained with the LaCoste-Romberg gravimeter ET-19 recording at BFO, for the strains (because of higher noise) time-series of only $8 \mathrm{~d}$. Of course, we should correct these observed strain amplitudes for the locally produced strain-strain coupling. We do this by dividing the observed amplitude by the coefficients in the first row of Table S2 in the Supporting Information. We then used eq. (6) to find estimates of Earth's radius $\tilde{R}_{\mathrm{E}}$. The results are listed in Table 2. Although the raw estimates are closer to the true radius than the corrected ones, they all give the correct order of magnitude. Thus, the observed vertical acceleration and horizontal strain amplitudes are geometrically consistent.

\section{COMPARISON OF STRAIN RECORDS FROM A BFO STRAINMETER WITH THE 1960 ISABELLA RECORD}

In the original papers on the famous Isabella strain record, an identification of the fundamental radial ('breathing') mode ${ }_{0} S_{0}$ is nowhere mentioned. Even for the strongest earthquakes the amplitude of this mode in strain is very small. As explained in the previous section, for a horizontal strainmeter of length $l$ the amplitude is given by the radial displacement amplitude $u_{\mathrm{r}}$ divided by the Earth's radius $R_{\mathrm{E}}$.

Widmer et al. (1992) reanalysed a digital version of that record to see if ${ }_{0} T_{2}$ could be identified using multiple taper spectral analysis but which turned out to be not the case (see the lower two panels of Fig. 8). However, in the spectrum of a $444 \mathrm{hr}$ record ${ }_{0} S_{0}$ could clearly be detected with an SNR at best of 3:1. Fig. 8 shows these spectra after multiplication with a Hann window of 60,140 and $444.5 \mathrm{hr}$ of this record.

For a qualitative comparison, we produced a similar diagram for the data from the $\mathrm{N} 2^{\circ} \mathrm{E}$ invar-wire strainmeter at BFO after the Aceh quake. Despite the lower moment magnitude of that quake ${ }_{0} S_{0}$ can be identified in all three panels of Fig. 9. Mode ${ }_{0} T_{2}$ can clearly be identified in the lower two panels of Fig. 9 as mentioned before. It is evident that despite the lower moment magnitude of the Aceh quake the SNR in each of the three spectra in Fig. 9 is superior to the ones in Fig. 8. Especially mode ${ }_{0} S_{0}$ has a much higher SNR in the new data. However, a more quantitative comparison of all the modes would have to take focal mechanism, source and station location and differing sensor azimuths into account. It is unknown whether the Isabella record could have been improved by application of a pressure correction as applied to the BFO data in previous figures of this paper. However, to make the comparison more fair the BFO records used for Fig. 9 were also not corrected for atmospheric pressure effects.

Although the SNRs for the modes are better for the modern records the quality of the Isabella strain record is impressive. This and a few other records added a new spectral range to seismology. It is basically to be expected that $44 \mathrm{yr}$ of technological progress would necessarily lead to improved SNRs. However, the basic strain sensors, their coupling to the Earth and their shielding have not changed that much, while the electronic displacement transducers, data acquisitions and timing accuracy have improved dramatically. The Isabella record is experimental proof that Hugo Benioff was an instrumental genius, and together with the new data shown in this study, highlights the strong potential of strain data for normal mode Earth structure and earthquake studies.

\section{DISCUSSION AND CONCLUSIONS}

For the lowest-frequency spheroidal and especially toroidal modes excited by the Aceh and Tohoku quakes, the observed SNRs in the BFO-strainmeter records were found to be superior to the SNRs obtained with the broad-band STS-1 horizontal seismometers up to about $1 \mathrm{mHz}$. We repeat here the fact that these seismometers at BFO provided some of the best quality data in the GSN as demonstrated by the detection of the horizontal Hum (Kurrle \& Widmer-Schnidrig 2008) with the data from these instruments. The quality difference is best seen for the modes ${ }_{0} S_{2},{ }_{0} T_{2}$ and ${ }_{2} S_{1}$. For both types of 

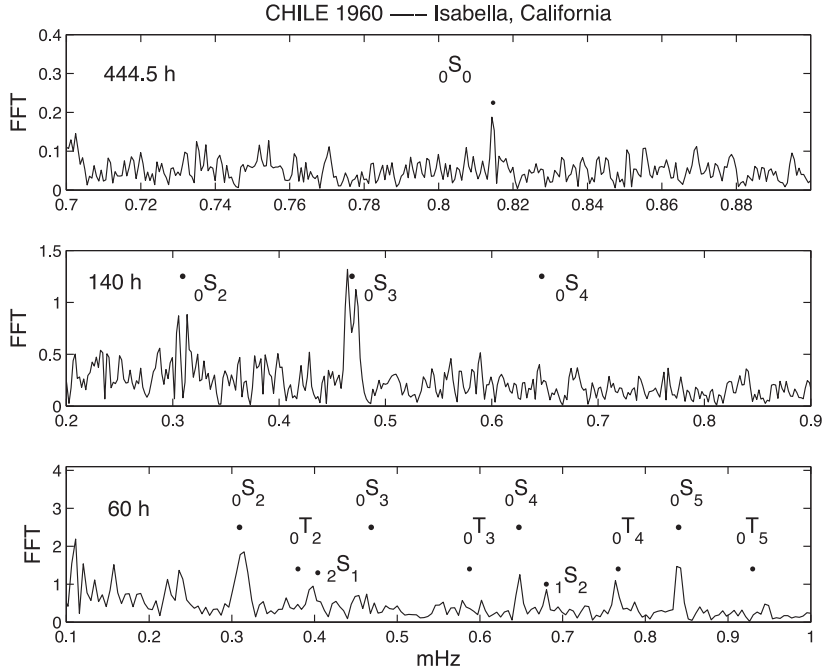

Figure 8. Spectra of a time-series from the Benioff $\mathrm{N} 32^{\circ} \mathrm{W}$-strainmeter at Isabella, California, starting on 1960 May 22 at 19:11:20 UTC, after the Great Chilean earthquake 1960. Different time-series lengths (multiplied by a Hann taper) were used to optimize the SNR for different modes having different $Q$ s. Top panel: $444.5 \mathrm{hr}$, needed to bring ${ }_{0} S_{0}$ out of the noise. Middle panel: $140 \mathrm{hr}$ needed to observe the rotational splitting of the low order fundamental spheroidal modes ${ }_{0} S_{2}$ and ${ }_{0} S_{3}$. Bottom panel: $60 \mathrm{hr}$ to look for the elusive fundamental toroidal mode ${ }_{0} T_{2}$ in this famous record.

instruments, significant parts of the noise induced by atmospheric pressure loading were removed by our barometric corrections.

The high quality of the strainmeters is also demonstrated by the facts (1) that these records are the first in which splitting of toroidal modes can be seen in an individual record, (2) that the fundamental radial mode ${ }_{0} S_{0}$ is observed with all three of them with good SNR at amplitudes of about $0.01 \mathrm{n} \epsilon$ and (3) that all three singlets of ${ }_{2} S_{1}$ are well above the noise for the Tohoku event, and last but not the least, (4) by the low noise PSD-values, lower than at PFO or any PBO strainmeter.

For the vertical broad-band seismometers, the agreement between observed and synthetic spectra for both events is almost perfect. For the strain and horizontal broad-band seismograms, the toroidal modes are rather well predicted for all components and events. The prediction for the overtones ${ }_{2} S_{1}$ and ${ }_{1} S_{2}$ is also satisfactory considering the SNRs. However, for these components the comparison of observed and synthetic spectra for the fundamental spheroidal modes ${ }_{0} S_{3},{ }_{0} S_{4}$ and to a lesser extent ${ }_{0} S_{2}$ and ${ }_{0} S_{5}$ leaves something to be desired.

Part of the problem might be associated with the modelling approach; for example, seismic source models are often determined dominantly from vertical component data due to their higher quality. Moreover, local structure effects may also play a role. More generally, our results agree with previous studies showing a better agreement between normal mode synthetics and data for vertical components than for horizontal component observations (e.g. Lentas et al. 2013). Not to be able to model horizontal accelerations as well as vertical ones without a clear understanding of the cause is of course a most unsatisfactory situation.

On a heterogeneous Earth the global strain fields of tides and normal modes produce additional local strains and local tilts (e.g. cavity effects) and the superposition of global and local signals is what is being sensed by strainmeters and horizontal seismometers. Cavity effects in tilt and strain recordings of the Earth Tides have been observed at BFO (and many other stations) and discussed in
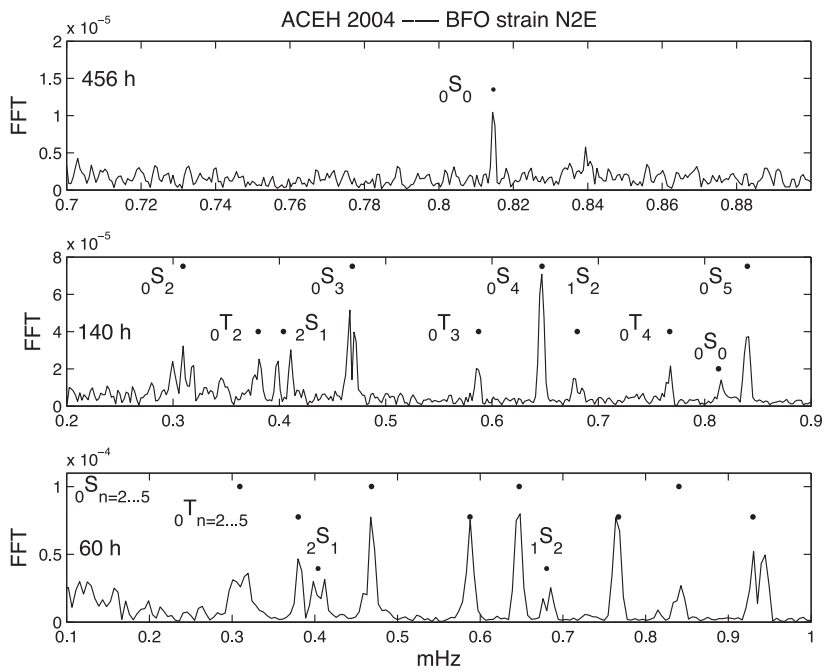

Figure 9. For comparison with Fig. 8: linear strain spectra of Hanned timeseries (lengths: 60, 140 and $456 \mathrm{hr}$ from bottom to top) after Aceh 2004 from the $\mathrm{N} 2{ }^{\circ} \mathrm{E}$ wire strainmeter at BFO. Although the quake was less energetic than the Chilean in 1960, the SNR in all three spectra is much improved in comparison to Fig. 8. Especially ${ }_{0} T_{2}$ is clearly identified here for the Aceh quake in the lower two spectra. No pressure correction was applied to the BFO strain data for this figure because the Isabella data were also not corrected.

previous studies (Berger \& Beaumont 1975; Emter \& Zürn 1985; Zürn \& Emter 1995).

In this paper, we demonstrate that local disturbances of the large scale strain fields for low-frequency normal modes occur which normally are not included in the synthetics. For horizontal accelerometers, this is demonstrated by the observations shown in Fig. B1 (Appendix B). It is also demonstrated for the strainmeters by the fact that the synthetics including strain-strain coupling fit the data better than synthetics without this coupling. This is by no means unexpected (King et al. 1976).

Park et al. (2008) used previous estimations of the coupling factors from tidal observations for their strainmeters at Gran Sasso and introduced them into their synthetics. We also estimated coupling coefficients for our strainmeters using the tidal records listed in the second paragraph of Section 3.1 and applied those to the synthetic strains (see Supporting Information Table S1). The modified synthetic spectra significantly reduced the misfits between predictions and observations. In our work on cavity effects at BFO, we have always conjectured that the locally produced signal-generated disturbances (the 'cavity effects') are neither dependent on frequency nor on the phenomenon driving the local inhomogeneities, and that coupling coefficients derived from tides can be applied to other quasi-static signals like the low-frequency free oscillations (King et al. 1976). This assumption was also implicitly taken by Park et al. (2008). Our tidally determined coefficients did improve the situation. It appears here that the conjecture holds in our case and that the tidally determined strain-strain-coupling coefficients help to explain low-frequency normal mode strain observations as well.

What are the physical conditions primarily responsible for strainstrain coupling in the case of the strainmeters and for strain-tilt coupling in the case of the horizontal accelerometers? In Fig. B1, we show that observed horizontal normal mode acceleration spectra differ significantly from installation to installation within the mine. This is with high probability due to strain-coupled tilts by the cavities in the rocks and has been studied previously using 
Earth tides (Emter \& Zürn 1985; Zürn \& Emter 1995; Lambotte 2007). The three $10 \mathrm{~m}$ long strainmeters, however, are installed in the centres of $60 \mathrm{~m}$ long tunnels with $2 \mathrm{~m}$ diameter and therefore tens of tunnel diameters away from the ends of the tunnels. These are conditions which minimize elastic disturbances (Harrison 1976) and the measured local strains should be very close to the strains at distance unless other features cause disturbances. Therefore topographic and rock heterogeneity effects rather than cavity effects must be invoked to explain the significant local effects in the strain observations. One interesting study made by Harrison (1976) concerns the strains observed in a two-dimensional hill, where at the top of the hill the observed strains in the direction perpendicular to the hillsides are reversed with respect to the strains applied at the base. Our largest effect, a reduction of the synthetic strain by 40 per cent occurs for the $\mathrm{N} 60^{\circ} \mathrm{E}$-instrument. The axis of the ridge in which BFO is located is nearly NS, so this strainmeter approximates Harrison's (1976) topographic model better than the other two. Since topography is rugged in the vicinity of BFO, that is the most likely candidate for the distortions in the strains (see Tables $\mathrm{S} 1$ and $\mathrm{S} 2$ in the Supporting Information).

Agnew \& Wyatt (2014) recently investigated seismic strains at stations in California and found large deviations from expectations, albeit at higher frequencies, where effects like focusing-defocusing and wave-front healing of surface waves play an important role. This is a completely different problem and not to be confused with the effects discussed in this paper.

It is well known that below about $1 \mathrm{mHz}$ the best superconducting gravimeters (including the help from again a barometric pressure correction) provide better SNRs for the spheroidal modes than the best vertical STS-1 seismometers (Widmer-Schnidrig 2003). A similar statement may be made for toroidal modes and the best strainmeters in comparison to the best horizontal STS-1s.

\section{ACKNOWLEDGEMENTS}

We thank Dieter Emter, Walter Großmann and Heinz Otto who were involved in the improvements of the Cambridge strainmeters, and Peter Duffner who maintains the instruments since 2005. AMGF and KL thank for support by the European Commission's Initial Training Network project QUEST (contract FP7-PEOPLE-ITN2008-238007, www.quest-itn.org). AMGF thanks for funding from IPGP for a visiting professorship in 2010-2011. The synthetics calculations presented in this paper were carried out on the High Performance Computing Cluster supported by the Research and Specialist Computing Support service at the University of East Anglia and at the UK NERC-EPSRC National Supercomputing facilities HECToR. Helpful comments and discussions by Thomas Forbriger, Rongjiang Wang, Helmut Wilhelm and Erhard Wielandt are appreciated. We also thank for the reviews provided by two anonymous reviewers which helped improving the paper. We are deeply indebted to Duncan C. Agnew for reviewing an early version of this paper, for a thorough and quick review of the submitted manuscript and for providing noise spectra from the laser strainmeters at PFO for our Fig. 3.

\section{REFERENCES}

Agnew, D.C., 1986. Strainmeters and tiltmeters, Rev. Geophys., 24, 579624.

Agnew, D.C. \& Wyatt, F.K., 2014. Dynamic strains at regional and teleseismic distances, Bull. seism. Soc. Am., 104, 1846-1859.
Araya, A., Takamori, A., Morii, W., Hayakawa, H., Uchiyama, T., Ohashi, M., Telada, S. \& Takemoto, S., 2010. Analyses of far-field coseismic crustal deformation observed by a new laser distance measurement system, Geophys. J. Int., 181, 127-140.

Barbour, A.J. \& Agnew, D.C., 2011. Noise levels on plate boundary observatory borehole strainmeters in Southern California, Bull. seism. Soc. Am., 101, 2453-2466.

Barbour, A.J. \& Agnew, D.C., 2012. Detection of Seismic Signals Using Seismometers and Strainmeters, Bull. seism. Soc. Am., 102, 2484-2490.

Benioff, H., 1959. Fused-quartz extensometer for secular, tidal, and seismic strains, Bull. geol. Soc. Am., 70, 1019-1032.

Benioff, H., Press, F. \& Smith, S.W., 1961. Excitation of the free oscillations of the Earth by earthquakes, J. geophys. Res., 66, 605-619.

Berger, J. \& Beaumont, C., 1975. An Analysis of Tidal Strain Observations from the USA II. The Inhomogeneous Tide, Bull. seism. Soc. Am., 66, 1821-1846.

Berger, J., Davis, P. \& Ekström, G., 2004. Ambient Earth noise: a survey of the global seismographic network, J. geophys. Res., 109, B11307, doi: 10.1029/2004JB003408.

Bogiatzis, P. \& Ishii, M., 2014. Constraints on the Moment Tensor of the 2011 Tohoku-oki earthquake from Earth's free oscillations, Bull. seism. Soc. Am., 104, 875-884.

Braitenberg, C. \& Zadro, M., 2007. Comparative analysis of the free oscillations generated by the Sumatra-Andaman Islands 2004 and Chile 1960 earthquakes, Bull. seism. Soc. Am., 97, S6-S17.

Butler et al., 2004. The global seismographic network surpasses its design goal, EOS, Trans. Am. geophys. Un., 85, 225-229.

Clévédé, E. \& Lognonné, P., 1996. Fréchet derivatives of coupled seismograms with respect to an anelastic rotating Earth, Geophys. J. Int., 124, 456-482.

Dahlen, F.A. \& Tromp, J., 1998. Theoretical Global Seismology, Princeton Univ. Press, 1044 pp.

Davis, P., Ishii, M. \& Masters, G., 2005. An assessment of the accuracy of GSN sensor response information, Seismol. Res. Lett., 76, 678-683.

Derr, J.S., 1969. Free oscillation observations through 1968, Bull. seism. Soc. Am., 59, 2079-2099.

Dziewonski, A.M. \& Anderson, D.L., 1981. Preliminary reference Earth model, Phys. Earth planet. Inter., 25, 297-356.

Dziewonski, A.M., Chou, T.-A. \& Woodhouse, J.H., 1981. Determination of earthquake source parameters from waveform data for studies of global and regional seismicity, J. geophys. Res., 86, 2825-2852.

Emter, D. \& Zürn, W., 1985 Observations of local elastic effects on earth tide tilts and strains, in "Earth Tides", in Benchmark Papers in Geology Series, pp. 309-327, ed. Harrison, J. C., Van Nostrand-Reinhold.

Farrell, W.E., 1972. Deformation of the Earth by surface loads, Rev. Geophys. Space Phys., 10, 761-797.

Ferreira, A.M.G., d'Oreye, N.F., Woodhouse, J.H. \& Zürn, W., 2006. Comparison of fluid tiltmeter data with long-period seismograms: surface waves and Earth's free oscillations, J. geophys. Res., 111, B11307, doi:10.1029/2006JB004311.

Fichler-Fettig, C., Grünewald, M. \& Zürn, W., 1986. Observation of spheroidal-toroidal mode coupling, Ann. Geophys., B3, 251-260.

Forbriger, T., 2007. Reducing magnetic field induced noise in broad-band seismic recordings, Geophys. J. Int., 169, 240-958.

Gilbert, F. \& Dziewonski, A.M., 1975. An application of normal mode theory to the retrieval of structural parameters and source mechanisms from seismic spectra, Phil. Trans. R. Soc. Lond., A, 278, 187-269.

Häfner, R. \& Widmer-Schnidrig, R., 2013. Signature of 3-D density structure in spectra of the spheroidal free oscillation ${ }_{0} S_{2}$, Geophys. J. Int., 192, 285294.

Harrison, J.C., 1976. Cavity and topographic effects in tilt and strain measurement, J. geophys. Res., 81, 319-328.

Jentzsch, G., Jahr, T., Letz, H. \& Gebauer, A., 2005. Erdeigenschwingungen nach dem Sumatra-Erdbeben vom 26. Dezember 2004 - beobachtet mit fünf ASKANIA-Bohrloch-Neigungsmessern an der KTB, Mittlg. Dt. Geophys. Ges., 1, 12-13.

King, G. \& Bilham, R., 1976. A geophysical wire strainmeter, Bull. seism. Soc. Am., 66, 2039-2047. 
King, G.C.P., Zürn, W., Evans, R. \& Emter, D., 1976. Site corrections for long-period seismometers, tilt- and strainmeters, Geophys. J. R. astr. Soc., 44, 405-411.

Kurrle, D. \& Widmer-Schnidrig, R., 2008. The horizontal hum of the Earth: a global background of spheroidal and toroidal modes, Geophys. Res. Lett., 33, L24304, doi:10.1029/2007/GL033125.

Lambotte, S., 2007. Vibrations propres basse fréquence et déformation de marée. Impact des hétérogénéités locales et contribution à 1 étude de la source des grandes séismes, Thèse de doctorat, Institut de Physique du Globe, Université Louis Pasteur, Strasbourg, France.

Lambotte, S., Rivera, L. \& Hinderer, J., 2006a. Rupture length and duration of the 2004 Aceh-Sumatra earthquake from the phases of the Earth's gravest free oscillations, Geophys. Res. Lett., L03307, doi:10.1029/2005GL024090.

Lambotte, S., Rivera, L. \& Hinderer, J., 2006b. Vertical and horizontal seismometric observations of tides, J. Geodyn., 41, 39-58.

Lentas, K., Ferreira, A.M.G. \& Vallée, M., 2013. Assessment of SCARDEC source parameters of global large $\left(M_{\mathrm{w}} \geq 7.5\right)$ subduction earthquakes, Geophys. J. Int., 195, 1989-2004.

Lentas, K., Ferreira, A.M.G., Clévédé, E. \& Roch, J., 2014. Source models of great earthquakes from ultra low-frequency normal mode data, Phys. Earth planet. Inter., 233, 41-67.

Lognonné, P. \& Clévédé, E., 2002. Normal Modes of the Earth and Planets, in Int. Handbook of Earthquake \& Engineering Seismology, Part A, pp. 125-147, eds Lee, W.H.K., Kanamori, H., Jennings, P.C. \& Kisslinger, C., Academic Press.

Longman, I.M., 1959. Formulas for computing the tidal accelerations due to the Moon and the Sun, J. geophys. Res., 64, 2351-2355.

Masters, G., Jordan, T.H., Silver, P.G. \& Gilbert, F., 1982. Aspherical Earth structure from fundamental spheroidal-mode data, Nature, 298, 609-613.

Okal, E.A., 2012. From 3-Hz P Waves to ${ }_{0} S_{2}$ : no evidence of a slow component to the source of the 2011 Tohoku earthquake, Pure appl. Geophys., 170, 963-973.

Park, J. et al., 2005. Earth's free oscillations excited by the 26 December 2004 Sumatra-Andaman earthquake, Science, 308, 1139-1144.

Park, J., Amoruso, A., Crescentini, L. \& Boschi, E., 2008. Long-period toroidal earth free oscillations from the great Sumatra-Andaman earthquake observed by paired laser extensometers in Gran Sasso, Italy, Geophys. J. Int., 173, 887-905.

Richter, B., Wenzel, H.-G., Zürn, W. \& Klopping, F., 1995. From Chandler wobble to free oscillations: comparison of cryogenic gravimeters and other instruments in a wide period range, Phys. Earth planet. Inter., 91, 131-148.

Ritzwoller, M. \& Lavely, E., 1995. Three-dimensional seismic models of the Earth's mantle, Rev. Geophys., 33(1), 1-66.

Rosat, S., Sato, T., Imanishi, Y., Hinderer, J., Tamura, Y., McQueen, H. \& Ohashi, M., 2005. High resolution analysis of the gravest seismic normal modes after the $2004 M_{\mathrm{w}}=9$ Sumatra earthquake using superconducting gravimeter data, Geophys. Res. Lett., L13304, doi:10.1029/2005GL023128.

Rosat, S., Watada, S. \& Sato, T., 2007. Geographical variations of the ${ }_{0} S_{0}$ normal mode amplitude: predictions and observations after the SumatraAndaman earthquake, Earth planets Space, 59, 307-311.

Roult, G., Rosat, S., Clévéde, E., Millot-Langet, R. \& Hinderer, J., 2006. New determinations of $\mathrm{Q}$ quality factors and eigenfrequencies for the whole set of singlets of the Earth's normal modes ${ }_{0} S_{0},{ }_{0} S_{2},{ }_{0} S_{3}$ and ${ }_{2} S_{1}$ using superconducting gravimeter data from the GGP network, J. Geodyn., 41, 345-357.

Smith, S.W., 1966. Free oscillations excited by the Alaskan earthquake, J. geophys. Res., 71, 1183-1193.

Stein, S. \& Okal, E.A., 2005. Speed and size of the Sumatra earthquake, Nature, 434, 581-582.

Takemoto, S. et al., 2004. A $100 \mathrm{~m}$ laser strainmeter system installed in a $1 \mathrm{~km}$ deep tunnel at Kamioka, Gifu, Japan, J. Geodyn., 38, 477-488.

Tanimoto, T., Ji, C. \& Igarashi, M., 2012. An approach to detect afterslips in giant earthquakes in the normal-mode frequency band, Geophys. J. Int., 190, 1097-1110.
Tsai, V.C., Nettles, M., Ekström, G. \& Dziewonski, A.M., 2005. Multiple CMT source analysis of the 2004 Sumatra earthquake, Geophys. Res. Lett., 32, L17304, doi:10.1029/2005GL023813.

Turcotte, D.L. \& Schubert, G., 1982, Geodynamics: Applications of Continuum Physics to Geological Problems, Wiley, $450 \mathrm{pp}$.

Widmer-Schnidrig, R., 2003. What can superconducting gravimeters contribute to normal mode seismology?, Bull. seism. Soc. Am., 93, 13701380.

Widmer-Schnidrig, R. \& Laske, G., 2007. Theory and Observationsnormal modes and surface wave measurements, in Treatise on Geophysics, Vol. 1, pp. 67-125, eds Romanowicz, B. \& Dziewonski, A., Seismology and Structure of the Earth.

Widmer, R., Zürn, W. \& Masters, G., 1992. Observation of low order toroidal modes from the 1989 Macquarie Rise event, Geophys. J. Int., 111, 226236.

Woodhouse, J.H. \& Dahlen, F.A., 1978. The effect of a general aspherical perturbation on the free oscillations of the Earth, Geophys. J. R. astr. Soc., 53, 335-354.

Zürn, W. \& Emter, D., 1995. Beobachtung von Hohlraumeffekten mit Seismometern im Observatorium Schiltach, in Festschrift Draheim-KuntzMälzer, pp. 289-304, Geodetic Institute, Karlsruhe University.

Zürn, W. \& Widmer-Schnidrig, R., 2002. Clear observations of ${ }_{0} T_{2}$ at BFO with invar-wire strainmeters, in Poster, Freeman Gilbert's 70th Birthday Symposium, p. 1, La Jolla.

Zürn, W. \& Wielandt, E., 2007. On the minimum of vertical seismic noise near $3 \mathrm{mHz}$, Geophys. J. Int., 168, 647-658.

Zürn, W., Exß, J., Steffen, H., Kroner, C., Jahr, T. \& Westerhaus, M., 2007. On reduction of long-period horizontal seismic noise using local barometric pressure, Geophys. J. Int., 171, 780-796.

Zürn, W., Laske, G., Widmer-Schnidrig, R. \& Gilbert, F., 2000. Observation of Coriolis coupled modes below $1 \mathrm{mHz}$, Geophys. J. Int., 143, $113-118$.

\section{SUPPORTING INFORMATION}

Additional Supporting Information may be found in the online version of this paper:

Table S1. Estimates of the strain-coupling coefficients (dimensionless) as defined in the equation in this Supporting Information. Numbers are only given to two decimal places.

Table S2. Estimates of the strain-coupling coefficients (dimensionless) as defined for coordinate systems aligned with each strainmeter. The coefficients $\mathrm{A}_{i, l l}, \mathrm{~A}_{i, q q}$ and $\mathrm{A}_{i, l q}$ are the coefficients multiplying the strain along the instrument, perpendicular to the instrument and shear strain in that coordinate system, respectively. If no cavity effect existed, all $\mathrm{A}_{i, l l}$ should be 1.00 and the $\mathrm{A}_{i, q q}$ and $\mathrm{A}_{i, l q}$ should be 0.00 . Numbers are only given to two decimal places. Figure S1. Time-series starting at 0:00:0.0 UTC on 2011 February 26 and $30 \mathrm{~d}$ long. Depicted are linear strains in azimuth $\mathrm{N} 60^{\circ} \mathrm{E}$ : the theoretical body tide (top) and the raw data from the St-4 invar-wire strainmeter (bottom). The oscillations recorded after the Tohoku megaquake (day $13=$ March 11) are easily recognized. While the amplitude of the observed strain is appreciably smaller than the predicted one before the quake due to a local elastic effect, the further diminishing of the observed tidal strain after the quake due to the loss of gain can clearly be identified. The data also show long-period noise partially due to atmospheric pressure loading.

Figure S2. Apparent tidal admittances estimated for the time period between the two absolute calibrations of the $\mathrm{N} 60^{\circ} \mathrm{E}$ instrument on 2011 January 26 and April 11 as described in the main paper and the text. These admittances are a representation of the strainmeter gain. The quake is indicated by a red vertical bar and the $220 \mathrm{hr}$ 
record used in the paper is indicated with the colour-shaded area. Short horizontal bars represent results for $3 \mathrm{~d}$ each, in black for the raw data and in red for the data after correction for the loss in gain. Thick green horizontal bars are results for five longer stretches of data. Before the quake the apparent gains are nicely centred on unity, while right after the quake they diminish quickly. Since the problem was later identified with a corroded cable, it is difficult to understand physically why this happened in time near this distant, albeit huge quake.

Figure S3. Selected apparent gains from the time after the Tohoku event (see Fig. S2) as a function of time (red circles). The blue curve is our representation of the instrumental gain as function of time with unity up to the time of the quake and a sixth degree polynomial afterwards. The quake is indicated by a red vertical bar and the $220 \mathrm{hr}$ record used in the paper is indicated with the yellow shaded area.

Figure S4. This figure is equivalent to Fig. 4 in the paper but here the strain synthetics do not include the local strain-coupling contribution.

Figure S5. This figure is equivalent to Fig. 5 in the paper but here the strain synthetics do not include the local strain-coupling contribution. (http://gji.oxfordjournals.org/lookup/suppl/doi:10.1093/ gji/ggv381/-/DC1)

Please note: Oxford University Press is not responsible for the content or functionality of any supporting materials supplied by the authors. Any queries (other than missing material) should be directed to the corresponding author for the paper.

\section{APPENDIX A: COMPARISON OF VERTICAL ACCELEROGRAMS WITH SYNTHETICS}

For reasons of completeness and for helping to find the source of our misfits, we compare the spectra of the STS-1 vertical accelerograms for the Aceh (Fig. A1) and Tohoku (Fig. A2) quakes with the synthetics computed as described above. Data were processed in the same way as with the horizontal accelerograms. For both events, the comparison of data with synthetics is excellent and much better than for the horizontals and the strains. We take the excellent fits as a justification for the source models used and for not using a heterogeneous mantle model in our synthetics.

\section{APPENDIX B: EVIDENCE FOR SIGNIFICANT LOCAL EFFECTS IN NORMAL MODE ACCELERATION SPECTRA}

At the time of the 2004 Aceh quake BFO was operating three horizontal accelerometers, both for the NS- and EW-direction: the STS1 and STS-2 broad-band seismometers, and the Askania borehole

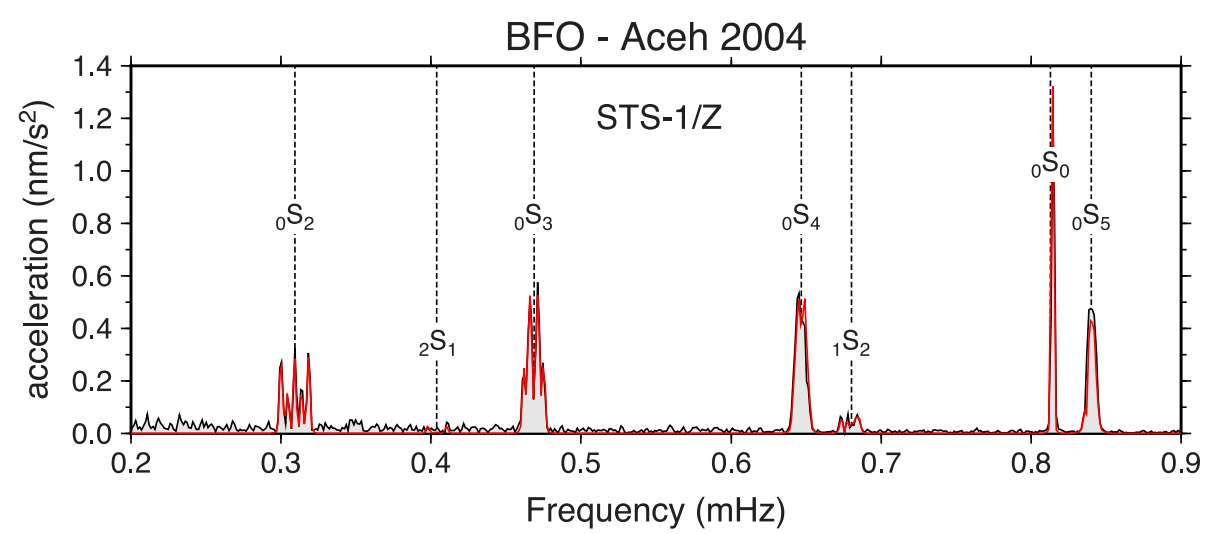

Figure A1. Spectrum of a $220 \mathrm{hr}$ acceleration time-series from the STS-1 vertical broad-band seismometer (black) and corresponding synthetics (red) at BFO after the Aceh quake. Time-series start at 2:30:00.0 UTC on 2004 December 26. Data were calibrated, instrument corrected, detided, corrected for air pressure effects and multiplied by a Hann taper before the Fourier transform. Calibrated air pressure was multiplied by $0.40 \mathrm{~nm} \mathrm{~s}^{-2} \mathrm{hPa}^{-1}$ and subtracted from the record. Dotted vertical lines represent degenerate multiplet frequencies from model 1066A (Gilbert \& Dziewonski 1975). The corresponding synthetic spectra are plotted in red.

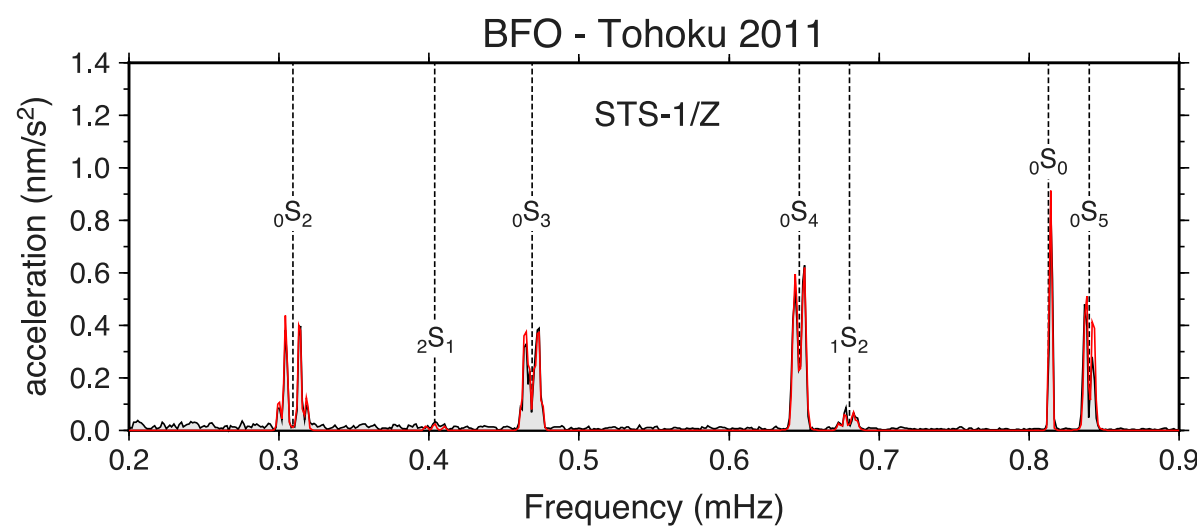

Figure A2. Same as Fig. A1 but for the Tohoku quake. Time-series start at 6:45:00.0 hr UTC on 2011 March 11. Calibrated air pressure and its Hilbert transform were multiplied by 3.3 and $-0.95 \mathrm{~nm} \mathrm{~s}^{-2} \mathrm{hPa}^{-1}$ and subtracted from the record. 

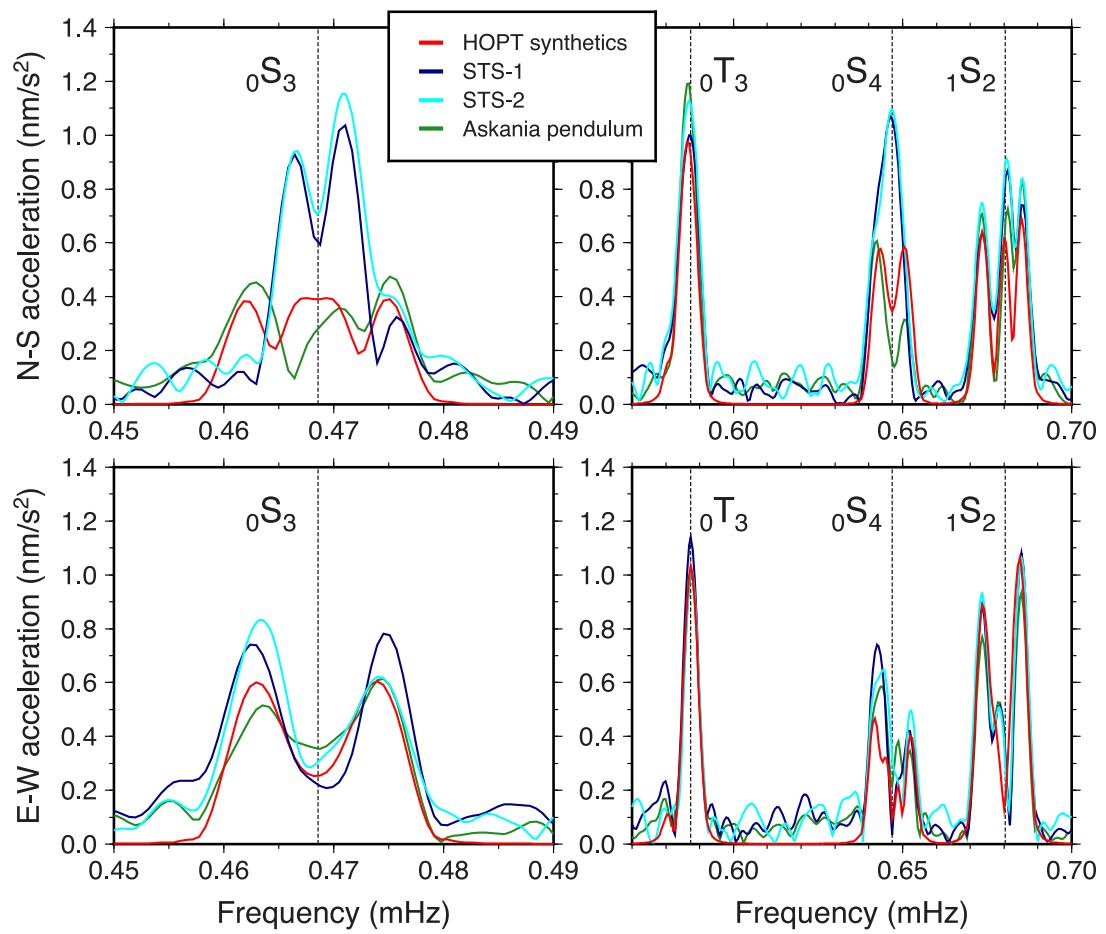

Figure B1. Spectra of data obtained from $120 \mathrm{hr}$ time-series after the Aceh quake from the STS-1, STS-2 and Askania tiltmeter and of the corresponding synthetics (see Section 4). Time-series start at 2:30:00.0 hr UTC on 2004 December 26. Before computing the FFT, a Hann window was applied and the time-series padded with zeros. NS-components are shown in the top panels, EW-components at the bottom. The left panels show fundamental spheroidal mode ${ }_{0} S_{3}$, the panels on the right the group fundamental toroidal mode ${ }_{0} T_{3}$, fundamental spheroidal mode ${ }_{0} S_{4}$ and spheroidal overtone ${ }_{1} S_{2}$.

tiltmeter (e.g. Agnew 1986). The first two are mounted less than $2 \mathrm{~m}$ apart on two adjacent piers in the seismic vault, both at the bottom of the southern wall (e.g. Zürn \& Emter 1995). The Askania borehole tiltmeter was mounted on the northern wall in the tiltmeter vault, about 105 m south of the seismic vault (e.g. Emter \& Zürn 1985).

In Fig. B1, we compare spectra of selected low-frequency modes obtained from these instruments and the synthetics for the Aceh quake. The time-series in this case were shortened to $120 \mathrm{hr}$ to improve the SNR, but start times are the same as in the main text. The data were calibrated, converted to acceleration where necessary (seismometers), detided and a pressure correction was applied as described in Section 3.2. Then a Hann taper was applied and the time-series were zero-padded before computing the FFTs. The synthetics were treated correspondingly.
Overall the Askania data are much better predicted by the synthetics than the seismometer data. The toroidal mode spectra all agree very well and the overtone spectra are also all very similar. The spectral shapes for the two seismometers agree fairly well with each other in all cases depicted. However, conspicuous discrepancies occur between seismometers on the one hand and Askania and synthetics on the other hand, especially for the NS-components, which must be explained by different local effects due to strain-tilt coupling at the different locations and by the different mounting of these instruments.

To determine strain-tilt coupling is beyond the scope of this paper but the observation presented in this appendix alone may be a key to understanding why low-frequency horizontal earthquake signals are notoriously worse fit by synthetics than vertical ones. 